\title{
Regulators of Oncogenic Mutant TP53 Gain of Function
}

\author{
Satomi Yamamoto ${ }^{1}$ and Tomoo Iwakuma ${ }^{1,2, *}$ \\ 1 Department of Cancer Biology, The University of Kansas Cancer Center, University of Kansas Medical \\ Center, Kansas City, KS 66010, USA; syamamoto@kumc.edu \\ 2 Department of Hematology and Oncology, Children's Mercy Research Institute, Kansas City, \\ MO 64108, USA \\ * Correspondence: tiwakuma@kumc.edu or tiwakuma@cmh.edu; Tel.: +1-913-588-7412
}

Received: 15 November 2018; Accepted: 18 December 2018; Published: 20 December 2018

check for updates

\begin{abstract}
The tumor suppressor p53 (TP53) is the most frequently mutated human gene. Mutations in TP53 not only disrupt its tumor suppressor function, but also endow oncogenic gain-of-function (GOF) activities in a manner independent of wild-type TP53 (wtp53). Mutant TP53 (mutp53) GOF is mainly mediated by its binding with other tumor suppressive or oncogenic proteins. Increasing evidence indicates that stabilization of mutp53 is crucial for its GOF activity. However, little is known about factors that alter mutp53 stability and its oncogenic GOF activities. In this review article, we primarily summarize key regulators of mutp53 stability/activities, including genotoxic stress, post-translational modifications, ubiquitin ligases, and molecular chaperones, as well as a single nucleotide polymorphism (SNP) and dimer-forming mutations in mutp53.
\end{abstract}

Keywords: TP53; mutant TP53; gain of function; post-translational modification; molecular chaperone; single nucleotide polymorphism; dimer-forming mutation

\section{Introduction}

The primary role of the tumor suppressor p53 (TP53) is to control cell cycle progression, senescence, DNA repair, cell death, and cell metabolism, leading to inhibition of tumorigenesis [1,2]. Compared to all other human genes, TP53 has the highest mutation rate, the majority of which are missense mutations with amino acid changes mainly in the DNA binding domain. There are hotspot mutations including R175, G245, R248, R249, R273, and R282, accounting for 30\% of p53 mutations [3]. In human cancers, the presence of mutant TP53 (mutp53) is associated with advanced stages of disease, metastasis, recurrence, and patient's poor prognosis, even when compared with TP53 deletion [4-6]. Such oncogenic activities of mutp53 are referred to as gain of function (GOF) [7]. Mutp53 GOF was first notified in 1993, when Dittmer et al. [8] observed that overexpression of R175H or R273H mutants in TP53-null Saos2 cells enhanced soft agar colony formation and tumor development in mice. Since then, considerable evidence has solidified that mutp53 not only loses wild-type TP53 (wtp53) function, but also enhances tumor malignancy in vitro and in vivo independent of wtp53.

The oncogenic function of mutp53 is mainly caused by altered structure and properties of mutp53 to bind with other oncogenic (e.g., Ets2, SREBPs, vitamin D receptor, NF-Y, AMPK) or tumor suppressive (e.g., TP63, TP73, Mre11) proteins [7,9-14]. Many of the mutp53 binding partners are transcription factors (Figure 1). The mutp53-protein interaction allows mutp53 to alter the function of these binding partners, showing unexpected oncogenic activities in cells. Detailed description about mechanisms of GOF and mutp53 binding partners is well-documented in many other excellent review articles [8,11,15-21]. As an additional mechanism, through studies of mutp53-knockin mice, Lozano's group demonstrate that mutp53 (mouse R172H, equivalent with human R175H) is inherently unstable, 
which can be accumulated by oncogenic and genotoxic stress similarly to wtp53, leading to enhanced cancer progression [22-25]. These studies strongly suggest that levels of mutp53 are crucial for the GOF activity. However, the mechanisms of GOF appear to be complicated and remain unsolved. This is mainly because not all TP53 mutants have the same activity and the biological properties of each mutp53 can be cellular context-dependent [15].

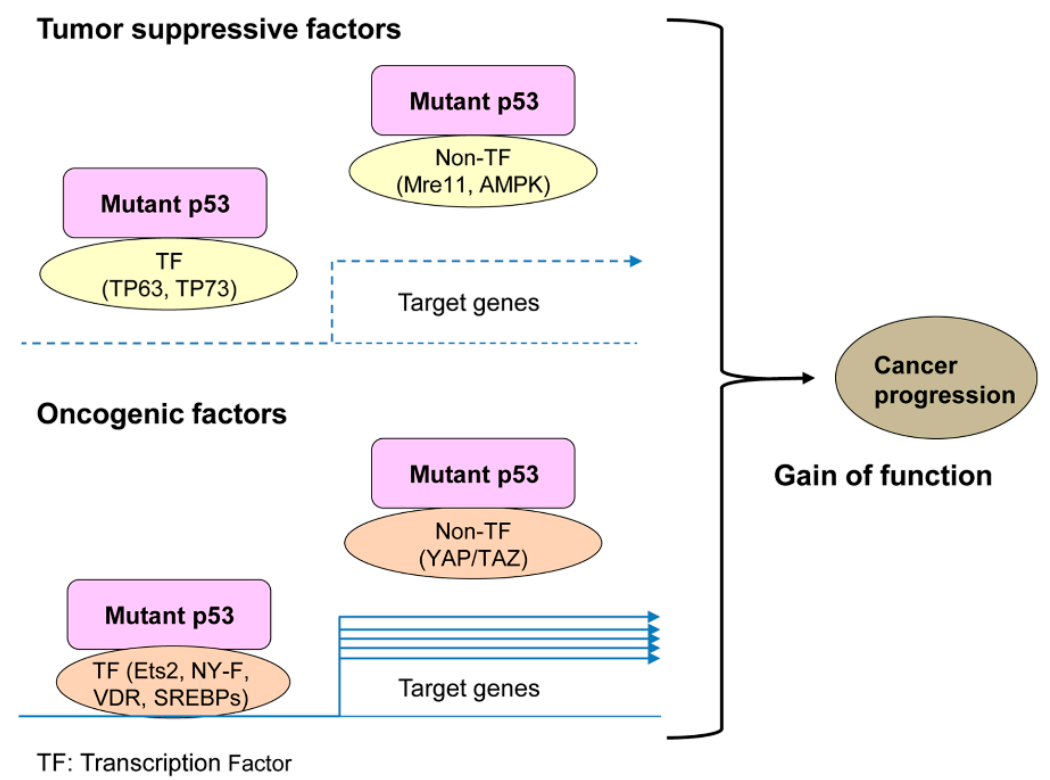

Figure 1. Mechanisms of mutant tumor suppressor p53 (mutp53) gain of function (GOF).

Generally, mutp53 can be roughly divided into two subtypes, DNA contact and conformational (or misfolded/unfolded) mutants. DNA contact mutants have mutations in amino acids where TP53 directly contacts with DNA, leading to impaired TP53's binding activity while sparing the intact TP53 structure. On the other hand, conformational mutants robustly alter the TP53 structure and disrupt the DNA binding activity [26,27]. As mentioned above, accumulation of mutp53 plays a crucial role in the oncogenic GOF activity. The mutp53 protein is often stabilized in cancer cells, whereas wtp53 has a short half-life in both normal tissues and cancer cells $[22,23,28]$. Recently, our group has shown that cholesterol-lowering drugs, statins, induce some TP53 mutants for CHIP (carboxyl terminus of HSC70-interacting protein/Stub1) ubiquitin ligase-mediated degradation depending on their structures (misfolded or not), because conformational or misfolded mutants are more sensitive to statin treatment than wtp53 and DNA contact mutants [29]. Additionally, Maan and Pai [30] demonstrate that TP53 mutants prone to aggregation are ubiquitinated and degraded by CHIP in hypoxic conditions. Thus, mechanisms behind mutp53 stability and degradation can be dependent on the structure and/or biochemical properties.

Like wtp53, mutp53 stability is regulated by various genotoxic stresses, nutrient depletion, and oncogenic or tumor suppressive proteins [23,25], which is mediated by multiple E3 ubiquitin ligases (e.g., MDM2: Mouse double minute 2, CHIP, Pirh2) and molecular chaperones (e.g., heat shock proteins: HSPs including HSP90, HSP70, and HSP40). In addition, mutp53 GOF activities can be altered by post-translational modifications (PTMs), such as phosphorylation, acetylation, and ubiquitination, as well as by a single nucleotide polymorphism at codon 72 (SNP72) and dimer-forming mutations. Although many review articles describe mutp53-binding partners and their downstream signaling as GOF mechanisms [8,15-21], a few reviews address upstream factors and PTMs that alter mutp53 stability and its oncogenic GOF activities which are the main focus of this review paper. 


\section{Mutp53 Stability and Activity Are Altered by Stress and Chemical Compounds}

Mutations in TP53 impair the transcriptional activity (loss of function: LOF). The majority of TP53 mutations are missense mutations. These dysfunctional TP53 mutant proteins are present in the cells and retain or gain abilities to bind with other proteins, resulting in altered function of these binding partners to enhance tumor malignancy, referred to as GOF [7,9-14] (Figure 1).

Due to mutp53's inability to transactivate downstream targets including its ubiquitin ligase MDM2, it was considered that mutp53 could be accumulated in both cancer and normal tissues. However, studies using mutp53 knockin mice have demonstrated that mutp53 levels are low in most normal tissues, while mutp53 is accumulated in many cancer tissues [22,23,31]. These in vivo studies also reveal that accumulation of mutp53 contributes to mutp53 GOF, such as shorter survival, more metastasis, and increased frequency of carcinoma (epithelial origin) incidence as compared to those in $\mathrm{TP}^{-1-} 3^{-/}$mice $[22,31]$. Additionally, these studies and others show that inherently unstable mutp53 can be stabilized by genotoxic stress (e.g., ionizing radiation, reactive oxygen species), oncogenic insults (e.g., Myc, K-Ras, ErbB2), and loss or inhibition of other tumor suppressive proteins (e.g., p16INK4A, IL27RA, PML: Promyelocytic leukemia) (Figure 2) [23,25,32-34]. Since most of these studies are demonstrated using $T P 53^{R 172 H}$-knockin mice, it remains unclear whether levels of other TP53 mutants also increase by these environmental stresses in mice.

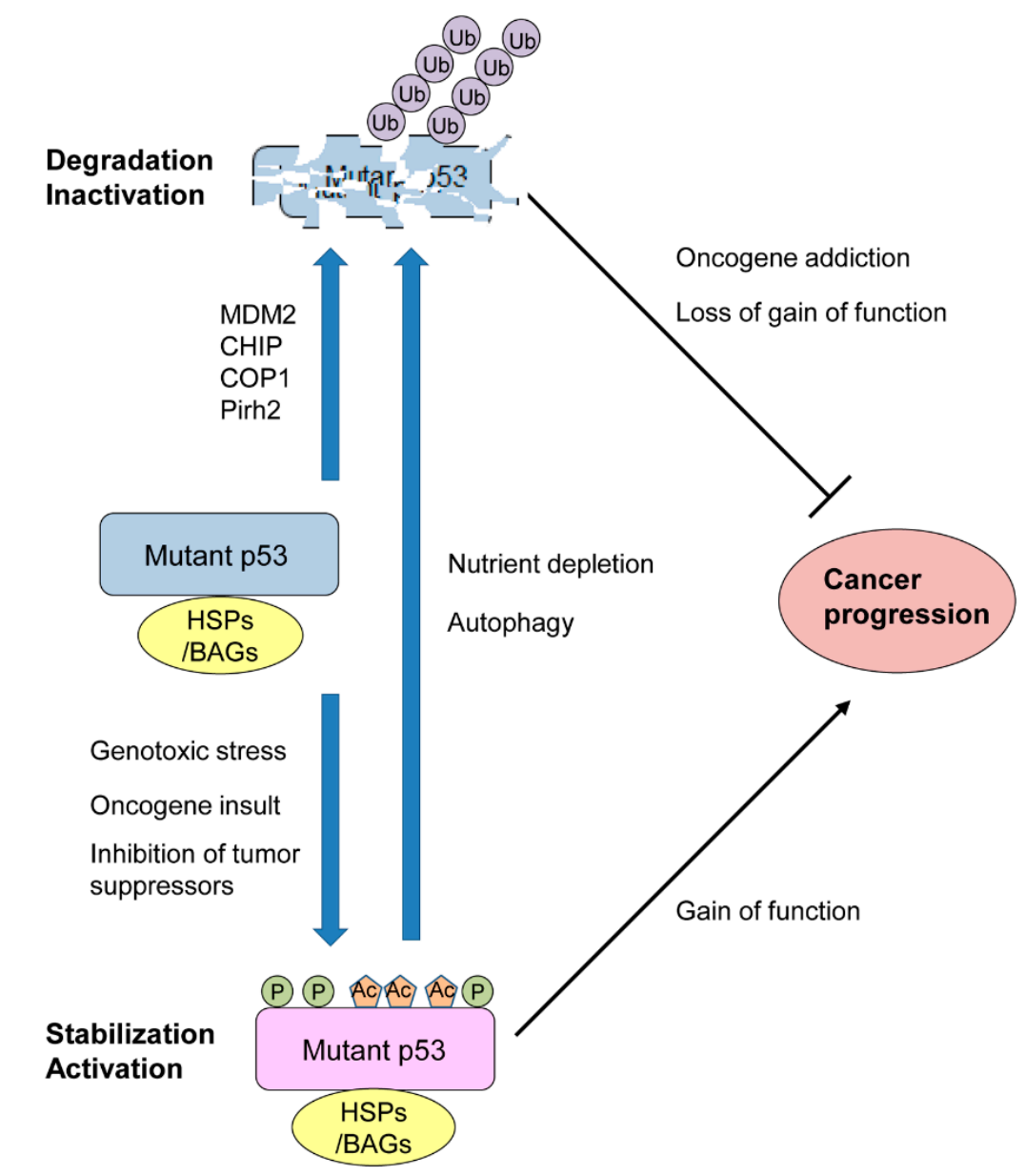

Figure 2. Environmental stresses alter stability and activity of mutant TP53 (mutp53) crucial for its oncogenic gain of function (GOF).

Mutp53 can be degraded by cellular conditions associated with autophagy (Figure 2). Suppression of macroautophagy by spautin- 1 under glucose free and confluent conditions induces degradation of mutp53 through chaperone-mediated autophagy (CMA) in a manner dependent on lysosome 
and independent of the ubiquitin-proteasome pathway [35,36]. Glucose restriction is also shown to induce deacetylation and degradation of multiple TP53 mutants (K132Q, R175H, L194F, R280K, R280T), which enhances activation of autophagic cell death and tumor suppression, since mutp53 inhibits autophagy (also mentioned in the acetylation section below) [36]. Furthermore, prolonged inhibition of the proteasome by MG132 treatment leads to degradation of multiple TP53 mutants (R175H, L194F, G245A, R280K), rather than stabilizing mutp53, via autophagy, since inhibition of autophagy by knocking down ATG5 and Ulk1 rescues MG132-induced mutp53 degradation [37,38]. Although these cellular stresses alter stability of mutp53, detailed molecular mechanisms remain to be clarified. Table 1 summarizes these regulators that directly alter mutp53 levels and/or its GOF activities.

By mainly focusing on the involvement of PTMs, specific chaperones, and ubiquitin ligases in mutp53 stability/activity, we briefly discuss chemical compounds that can alter mutp53 stability/ activity. These include mutp53 accumulators (e.g., DNA damage agents), degraders/depleters (e.g., arsenic compounds, statins, HSP90 inhibitors, histone deacetylase inhibitor: HDACi, spautin-1, gambogic acid, phenformin), and reactivators (e.g., PRIMA-1, APR-246, MIRA1/2/3, STIMA-1, RITA, NSC319726/ZMC1, chetomin, stictic acid, p53R3, SCH529074, WR-1065, thiosemicarbazones, PhiKan083, CP-31398, PK7088) [7,39-42].

DNA damage agents result in increased levels of mutp53 to alter function of TP53-binding partners, which contributes to chemoresistance [24,43-46]. For example, a chemotherapy agent, Gemcitabine, is shown to phosphorylate mutp53 (R273H) at serine 15, leading to nuclear accumulation of mutp53, which increases chemoresistance [41,47]. Do et al. [46] also demonstrate that several TP53 mutants including R175H and R248W bind to Ets2, which upregulates expression of TDP2, a 5'-tyrosyl DNA phosphodiesterase involved in DNA repair, leading to etoposide resistance.

Cancer cells are frequently addicted to mutp53, since knockdown of TP53 mutants attenuates malignant properties of cancer cells and tumor development in mice [48]. Tumor suppression induced by mutp53 knockdown may also be caused by reactivation of proteins (e.g., TP63, TP73) which are inhibited by mutp53. These provide rationale to identify mutp53 degraders/depleters for mutp53-targeted cancer therapy. Inhibitors of HSP90 have been shown to attenuate lymphoma and colon cancer progression via mutp53 (R248Q, mouse R172H) degradation in spontaneous mouse models [49,50]. Additionally, statins are shown to reduce mutp53 [29,51]. Parrales et al. [29] show that several statins including lovastatin and atorvastatin promote degradation of mainly misfolded or conformational mutp53 by inhibiting its interaction with HSP40 (DNAJA1) in a CHIP-ubiquitin ligase dependent manner, resulting in inhibited tumor malignancy and progression in xenograft mouse models. It should be noted that levels of DNA contact mutp53 also reduce, to some extent, at a higher concentration of lovastatin. Similarly, Ingallina et al. [51] report that cerivastatin induces MDM2-mediated degradation of several TP53 mutants by inhibiting interaction between mutp53 and HSP90, leading to reduce colony formation of MDA-MB-231 cells [51]. Importantly, some of HSP90 inhibitors and statins are in cancer clinical trials (https:/ / clinicaltrials.gov/).

Many TP53 mutants are structurally altered, especially in the DNA binding domain, thereby losing the DNA binding potential [52]. Researchers have attempted to identify compounds that restore wtp53 activity in cells expressing only mutp53 through cell-based (PRIMA-1, MIRA1, thiosemicarbazones, chetomin, RITA, NSC319726/ZMC1, p53R3, SCH529074, WR1065) or structure-based (stictic acid, PhiKan083, CP-31398, PK7088) screens [39]. APR-246 is a methylated analog of PRIMA-1, while MIRA2/3 are analogs of MIRA1. One of the potential mechanisms of reactivator compounds is the promotion of refolding of wtp53 structure directly (e.g., refolding promotion by stabilization of the TP53 core domain) or indirectly (e.g., refolding through molecular chaperones). They may also bind to and stabilize a residual population of mutp53 with pre-existing wtp53 conformation [53-55]. Alternatively, some reactivators may increase transcriptional activities of TP53 family members, TP63 and TP73, since both TP63 and TP73 recognize the same DNA sequence as TP53. Most of these compounds successfully upregulate some of TP53 target genes; however, only a few compounds, including PRIMA-1, p53R3, and chetomin, are shown to restore mutp53's ability to bind to the TP53-responsive element [56-58]. 
Although the exact mechanisms of mutp53 reactivation remain to be elucidated, these reactivators have been shown to efficiently induce cell cycle arrest or apoptosis in vitro and in vivo to suppress tumor malignancy and progression $[39,53]$. Hence, reactivators have been shown to successfully overcome the mutp53 GOF activity by restoring wtp53 function. It should be noted that APR-246 is currently in Phase II clinical trials for cancers carrying mutp53 (https: / clinicaltrials.gov/).

Accumulated studies demonstrate efficacy of mutp53 degraders/depleters and reactivators to inhibit tumor progression in vitro and in vivo; however, it remains unclear whether these compounds cause PTMs of mutp53 and if the PTMs induced by them play crucial roles in mutp53 degradation or reactivation.

\section{PMTs of Mutp53}

Wtp53 is post-translationally modified following a variety of genotoxic and cellular stresses at approximately $15 \%$ of amino acid residues, including serine, threonine, and lysine residues, through phosphorylation, acetylation, and ubiquitination [59-61]. Mutp53 is also modified similarly, but the biological consequences are completely different from those by wtp53. This is mainly because a stress stabilizes and activates wtp53 resulting in suppression of cancer progression as a tumor suppressor, whereas the same stress can stabilize mutp53 leading to exacerbated tumor malignancy by the oncogenic GOF. It is also possible that mutp53 is modified through other PTMs like wtp53, including methylation [62], SUMOylation [62], neddylation [62], ADP ribosylation [63], methionine oxidation [64,65], cysteine alkylation [66], and tyrosine nitration [67]; however, little is known about these effects on the stability, subcellular localization, and activity of mutp53 in cancer cells. Figure 3 summarizes PTMs, molecular chaperones, and amino acid residues which are potentially involved in mutp53 stability/activity.
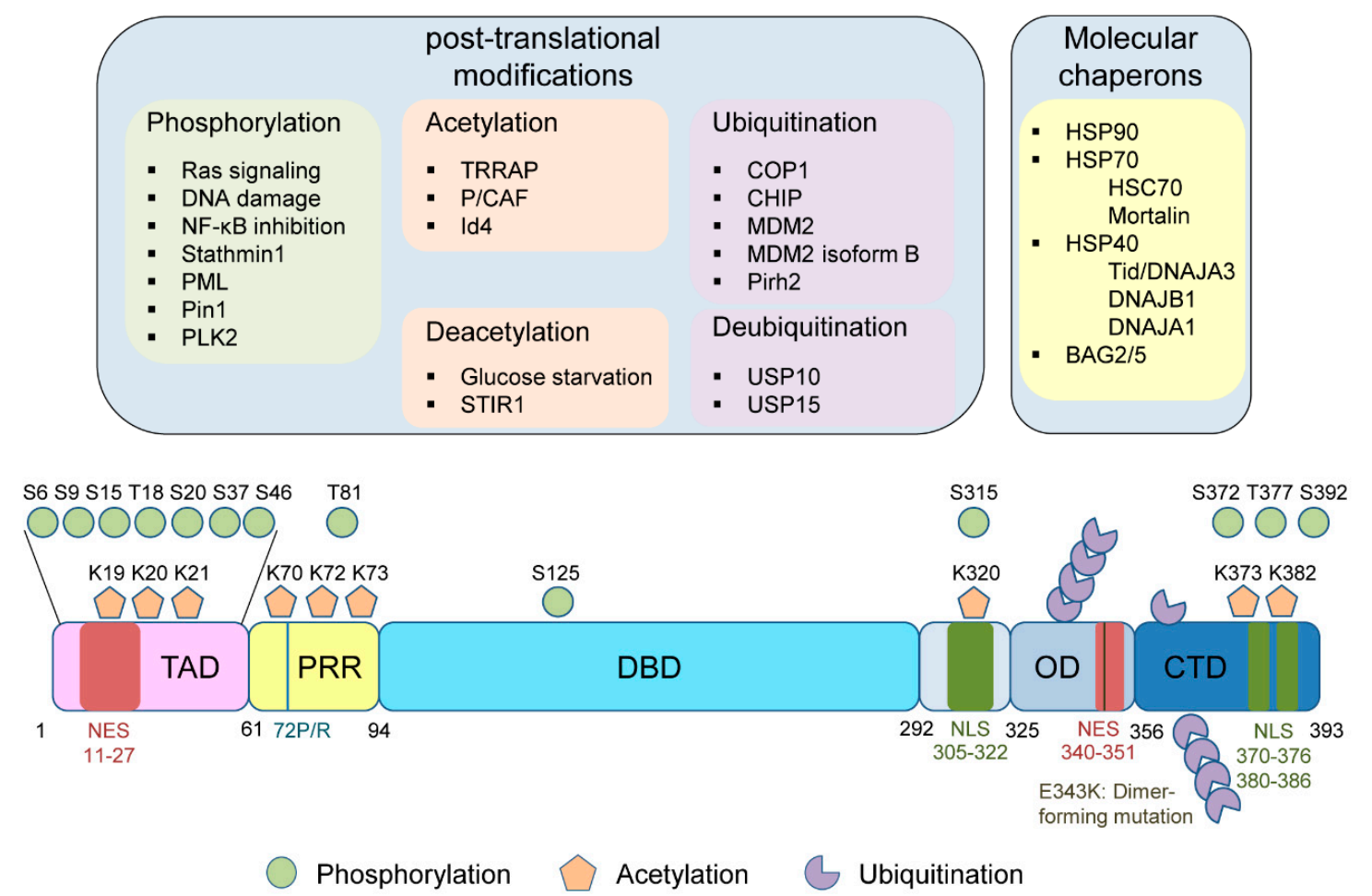

Figure 3. Upstream factors regulating mutant TP53 (mutp53) stability and activity, including post-translational modifications (PTMs) and molecular chaperones, as well as single nucleotide polymorphism 72 (SNP72) and dimer-forming mutations, in mutp53. TAD: Transactivation domain, PRR: Proline-rich region, DBD: DNA binding domain, NLS: Nuclear localization signal, OD: Oligomerization domain, NES: Nuclear export signal, CTD: C-terminal domain. 


\subsection{Phosphorylation}

Phosphorylation of proteins is one of the major mechanisms for regulating protein stability or function and transmitting signals in the cell. Following various stresses, wtp53 is phosphorylated at several serine/threonine residues, including serine 15 (S15), threonine 18 (T18), serine 20 (S20), serine 46 (S46), and serine 392 (S392) [59]. Intriguingly, these phosphorylation sites are rarely mutated in cancers [68]. Although mutp53 is also phosphorylated, the effects on mutp53 stability and activity are less understood as compared with those on wtp53 (Figure 3) [69,70].

Ullrich et al. [71] report that in glioma and adenocarcinoma cell lines, TP53 mutants (M237I and V143A) are less phosphorylated at S15 but are more phosphorylated at S392 as compared to wtp53. Minamoto et al. [72] also observe that mutp53 is phosphorylated at various sites including S9, S15, S20, S37, S46, T81, S125, S372, and S392 in human tumors. Intriguingly, the site and extent of phosphorylation are cell line-dependent, although S15, T81, and S392 appear to be more frequently phosphorylated among these serine and threonine residues. Below are studies that show functional changes in mutp53, accompanied with the corresponding phosphorylation (Table 1). 
Table 1. Regulators that alter mutant TP53 stability and activity.

\begin{tabular}{|c|c|c|c|c|c|}
\hline Upstream Regulators & Mutant TP53 & $\begin{array}{l}\text { Modified } \\
\text { Amino Acids }\end{array}$ & Samples/Cell Lines & Outcomes/Effects & References \\
\hline \multicolumn{6}{|l|}{ Phosphorylation } \\
\hline Ras signaling & R280K & S6, S9 & MDA-MB-231 & Mutp53/Smad2/TP63 Complex inhibit TP63's metastasis suppressor function. & [73] \\
\hline DNA damage & R248W, R273H & S15 & MEFs, PANC1 & $\begin{array}{l}\text { Constitutively activated DNA damage could account for mutp53 stabilization } \\
\text { or nuclear accumulation via S15 phosphorylation. }\end{array}$ & {$[41,47,74]$} \\
\hline $\begin{array}{l}\text { NF- } \mathrm{KB} \text { inhibition by IкB } \\
\text { overexpression }\end{array}$ & P223L/V274V & S15 & DU145 & $\begin{array}{l}\text { NF-kB inhibition in DU145 cells leads to S15 phosphorylation of mutp53 via } \\
\text { GADD45 } \alpha \text {-mediated JNK1 activation and potential restoration of wtp53. }\end{array}$ & [75] \\
\hline Stathmin 1 & R175H, R273H & S15, S37 & TOV112D, MDAH-2774 & $\begin{array}{l}\text { Stathmin1 enhances interaction of mutp53 with DNA-PK, phosphorylation of } \\
\text { mutp53 at S15 and S37 by DNA-PK, and mutp53 stabilization, leading to } \\
\text { increased viable cell proliferation. }\end{array}$ & [76] \\
\hline PML & $\begin{array}{l}\text { R175H, R273H, } \\
\text { R273H/P309S }\end{array}$ & $\begin{array}{l}\text { Not specified (maybe via } \\
\text { phosphorylation at T18 } \\
\text { and S46 in mutp53 } \\
\text { likewise wtp53) }\end{array}$ & SKBR3, HT29, SW48 & $\begin{array}{l}\text { PML interacts with mutp } 53 \text { and is required for proliferation and colony } \\
\text { formation of cancer cells bearing mutp53; however, it is unclear whether PML } \\
\text { promotes phosphorylation of mutp } 53 \text { like wtp } 53 \text {. }\end{array}$ & [77] \\
\hline Pin1 & Mouse R172H, R280K & $\begin{array}{l}\text { Not specified (maybe via } \\
\text { isomerization of } \\
\text { phosphorylated S46-P47 } \\
\text { site in mutp53 likewise } \\
\text { wtp53) }\end{array}$ & MEFs, MDA-MB-231 & $\begin{array}{l}\text { Homozygous deletion of Pin1 attenuates tumor progression in } \\
T P 53^{R 172 H / R 172 H} \text { mice, while Pin1 enhances migration and lung colonization of } \\
\text { MDA-MB-231 cells in a manner dependent on mutp53 by enhancing } \\
\text { inhibitory interaction of mutp53 with TP63; however, it is unclear whether } \\
\text { observed phenotypes by Pin1 are mediated through its detection of } \\
\text { phosphorylated S46-P47 site in mutp53. }\end{array}$ & [78] \\
\hline PLK2 & $\mathrm{R} 175 \mathrm{H}, \mathrm{R} 273 \mathrm{H}$ & T377 & H1299, SKBR3 & $\begin{array}{l}\text { PLK2 phosphorylates mutp53 at T377 and enhances binding of mutp53 with } \\
\text { p300, acetylation of mutp53, and mutp53 GOF activity, including increased } \\
\text { cell proliferation, NF-Y's transcriptional activity, and Adriamycin resistance. }\end{array}$ & [79] \\
\hline $\begin{array}{l}\text { Not specified/oncogenic } \\
\text { signaling }\end{array}$ & Not Specified & S392 & $\begin{array}{c}\text { Cancer tissues (esophageal } \\
\text { squamous cell carcinoma, } \\
\text { urothelial transitional cell } \\
\text { carcinoma) }\end{array}$ & $\begin{array}{l}\text { S392 phosphorylation in mutp53 is correlated with high levels of Ki67 } \\
\text { staining, lymphatic invasion, and poor prognosis, as well as enhanced } \\
\text { hetero-oligomerization with wtp53 and dominant-negative activities. }\end{array}$ & {$[70,80,81]$} \\
\hline \multicolumn{6}{|l|}{ Acetylation } \\
\hline TRRAP & $\begin{array}{c}\text { R248Q, R248W, } \\
\text { R283H/G245SS, } \\
\text { R213Q/Y234H, I254D, } \\
\text { R273H }\end{array}$ & Not specified & $\begin{array}{l}\text { BL-41, BL-60, CA-46, DG-75, } \\
\text { Namalwa, Raji, Ramos, } \\
\text { SUDHL-4, Colo320 }\end{array}$ & $\begin{array}{l}\text { TRAPP recruits HATs to chromatin and increases acetylation and } \\
\text { accumulation of mutp53 through inhibition of MDM2-mediated degradation. }\end{array}$ & [82] \\
\hline $\mathrm{P} / \mathrm{CAF}$ & R175H, G245A, D281G & K320, K373 & H1299 & $\begin{array}{l}\text { Treatment of cells with TSA acetylates mutp } 53 \text { at K } 320 \text { and K373 by P/CAF to } \\
\text { increase apoptosis with enhanced DNA binding of mutp53 to the } p 21 \text { and } \\
\text { PUMA promoters. }\end{array}$ & [83] \\
\hline Id 4 & P223L/V274F & K320, K373 & DU145 & $\begin{array}{l}\text { Id4 increases interaction of mutp } 53 \text { with CBP/p300, acetylation at K320 and } \\
\text { K373 on mutp53, and apoptosis with upregulation of p21, BAX, and PUMA. }\end{array}$ & [84] \\
\hline
\end{tabular}


Table 1. Cont

\begin{tabular}{|c|c|c|c|c|c|}
\hline Upstream Regulators & Mutant TP53 & $\begin{array}{l}\text { Modified } \\
\text { Amino Acids }\end{array}$ & Samples/Cell Lines & Outcomes/Effects & References \\
\hline \multicolumn{6}{|l|}{ Deacetylation } \\
\hline Glucose restriction & G245A & $\begin{array}{l}\text { Not specified (6Q } \\
\text { mutations in K319, K320, } \\
\text { K321, K370, K372, K373) }\end{array}$ & H1299 & $\begin{array}{l}\text { G245A-K6Q shows resistance to mutp53 degradation and cell death induced } \\
\text { by glucose restriction. }\end{array}$ & [36] \\
\hline SIRT1 & $\begin{array}{l}\text { R249S, R273H, V157F, } \\
\text { M237I }\end{array}$ & K382 & $\begin{array}{l}\text { BT549, MDA-MB-468, HS578T, } \\
\text { SUM149PT }\end{array}$ & $\begin{array}{l}\text { Activation of SIRT1 deacetylase by YK-3-237 decreases mutp53 levels with } \\
\text { reduced acetylation at K382, leading to induction of apoptotic cell death and } \\
\text { G2/M cell cycle arrest with induction of wtp53 target genes. }\end{array}$ & [85] \\
\hline \multicolumn{6}{|l|}{ Ubiquitination } \\
\hline $\begin{array}{c}\text { COP1, CHIP } \\
\text { (independent of MDM2) }\end{array}$ & $\mathrm{R} 175 \mathrm{H}$ & Not specified & $\begin{array}{c}\mathrm{U} 2 \mathrm{OS}, \mathrm{H} 1299, \\
M D M 2^{-l-} \mathrm{TP}^{-1-} \mathrm{MEFs}\end{array}$ & $\begin{array}{l}\text { Downregulation of COP1 or CHIP reduces ubiquitination of mutp53 } \\
\text { independent of MDM2. }\end{array}$ & [86] \\
\hline $\begin{array}{l}\text { Not } \\
\text { specified/MDM2-independe } \\
\text { ubiquitination }\end{array}$ & nt C135Y, V143A, H179E & Not specified & $\begin{array}{l}\mathrm{U} 2 \mathrm{OS}, \mathrm{MDM}^{-/-} \mathrm{TP}^{-1-} \\
\text { MEFs }\end{array}$ & $\begin{array}{l}\text { Misfolded mutp53 is more efficiently ubiquitinated and localizes to the } \\
\text { cytoplasm to a greater extent than a DNA contact mutp53 (R248W). }\end{array}$ & [87] \\
\hline MDM2 & $\mathrm{R} 273 \mathrm{H}$ & Not specified & H1048, H1299, WI38 & $\begin{array}{l}\text { S15 phosphorylation of mutp53 by ATM following DNA damage inhibits } \\
\text { MDM2-mediated polyubiquitination and degradation of mutp53 with } \\
\text { allowing its monoubiquitination and accumulation. }\end{array}$ & [88] \\
\hline $\begin{array}{l}\text { MDM2 isoform B } \\
\text { (MDM2-B) }\end{array}$ & $\begin{array}{l}\text { R175H, R248W, R273H, } \\
\text { Y220C S241F }\end{array}$ & Not specified & $\begin{array}{l}\text { H1299, HCT116, T47D, Huh7, } \\
\text { DLD-1 }\end{array}$ & $\begin{array}{l}\text { MDM2-B binds to and inhibits full-length MDM2 (MDM2-FL)-mediated } \\
\text { mutp53 degradation, leading to enhanced mutp53 GOF activities to promote } \\
\text { tumor growth and metastasis. }\end{array}$ & [89] \\
\hline CHIP & R156P, R175H, Y220C & Not specified & $\begin{array}{l}\text { KHOS/NP, SKBR3, CAL33, } \\
\text { BXPC3 }\end{array}$ & $\begin{array}{l}\text { Cholesterol-lowering drugs "statins," knockdown of mevalonate kinase, and } \\
\text { DNAJA1 knockdown induce CHIP-mediated nuclear export and degradation } \\
\text { of mainly conformational/misfolded mutp53. }\end{array}$ & [29] \\
\hline CHIP & R110P, R175H & Not specified & HCT116, CAL33 & $\begin{array}{l}\text { Aggregating TP53 mutants (R110P, R175H), but not non-aggregating mutants } \\
\text { (R248W, R273H), are ubiquitinated and degraded by CHIP via K63-linked } \\
\text { polyubiquitination in a manner dependent on autophagy. }\end{array}$ & [30] \\
\hline Pirh2 & $\begin{array}{c}\text { R175H, R248W, } \\
\text { H179Y/R282W, R273H }\end{array}$ & Not specified & $\begin{array}{l}\text { SW480, MiaPaCa-2, HaCaT, } \\
\text { HCT116 }\end{array}$ & $\begin{array}{l}\text { Arsenic trioxide (ATO) induces Pirh2-mediated degradation of multiple TP53 } \\
\text { mutants. }\end{array}$ & [90] \\
\hline \multicolumn{6}{|l|}{ Deubiquitination } \\
\hline USP10 & Not specified & Not specified & $786-\mathrm{O}$ & $\begin{array}{l}\text { USP10 overexpression inhibits MDM2-mediated mutp53 ubiquitination } \\
\text { leading to stabilization of mutp53 as well as increased colony formation and } \\
\text { cell proliferation. }\end{array}$ & [91] \\
\hline USP15 & $\mathrm{R} 175 \mathrm{H}$ & Not specified & TYK-Nu, TOV112D, SKOV3 & $\begin{array}{l}\text { MCB-613, a stimulator of steroid receptor coactivators (SRCs), enhances } \\
\text { nuclear export, ubiquitination, and lysosome-mediated degradation of } \\
\text { mutp53 (R175H), but not R273H, through inhibition of USP15, leading to } \\
\text { reduced viability of ovarian cancer cells. }\end{array}$ & [92] \\
\hline
\end{tabular}


Table 1. Cont

\begin{tabular}{|c|c|c|c|c|c|}
\hline Upstream Regulators & Mutant TP53 & $\begin{array}{c}\text { Modified } \\
\text { Amino Acids }\end{array}$ & Samples/Cell Lines & Outcomes/Effects & References \\
\hline \multicolumn{6}{|l|}{ Molecular Chaperons } \\
\hline HSP90 & $\begin{array}{l}\text { L194F, S241F, R273C, } \\
\text { R273H }\end{array}$ & N/A & $\begin{array}{l}\text { T47D, DLD1, C33A, } \\
\text { MDA-MB-468 }\end{array}$ & $\begin{array}{l}\text { HSP90 forms a complex with MDM2 and mutp53 to block ubiquitination of } \\
\text { both MDM2 and mutp53, while HSP90 inhibition by geldanamycin induces } \\
\text { MDM2-mediated mutp53 degradation. }\end{array}$ & [93] \\
\hline HSP90 & $\begin{array}{l}\text { R175H, L194F, } \\
\text { P223L/V274F, R273H, } \\
\text { R273H/P309S, R280K, } \\
\text { R280T }\end{array}$ & N/A & $\begin{array}{l}\text { SKBR3, T47D, DU145, } \\
\text { MDA-MB-468, MDA-MB-231, } \\
\text { SW480, 5637 }\end{array}$ & $\begin{array}{l}\text { HSP } 90 \text { forms a complex with mutp } 53 \text { to prevent mutp53's aggregation by } \\
\text { inhibiting MDM2 and CHIP activities. }\end{array}$ & [94] \\
\hline $\begin{array}{l}\text { HSP90 } \\
\text { (HDAC6-HSP90-mutp53 } \\
\text { complex) }\end{array}$ & $\begin{array}{c}\text { R175H, L194F, } \\
\text { P223L/V274F, S241F, } \\
\text { R273H/P309S, R280K }\end{array}$ & N/A & $\begin{array}{l}\text { SKRB3, T47D, DU145, ES2, } \\
\text { SW480, MDA-MB-231 }\end{array}$ & $\begin{array}{l}\text { Inhibition of HSP90 activity by SAHA releases mutp53 from the } \\
\text { HDAC6-HSP90-mutp53 complex, leading to mutp53 degradation by MDM2 } \\
\text { and CHIP to enhance cell death by a chemotherapy agent, Camptothesin. }\end{array}$ & [95] \\
\hline HSP90 & mouse R172H and R248Q & N/A & T-lymphomas & $\begin{array}{l}\text { Inhibition of HSP90 by ganetespib results in degradation of mutp53 in } \\
\text { lymphomas and prolongs survival of } T P 53^{R 172 H / R 172 H} \text { and } T P 53^{R 248 Q /-} \text { mice } \\
\text { with minimal effects on TP53-null mice. }\end{array}$ & [50] \\
\hline $\begin{array}{l}\text { HSP90 } \\
\text { (HDAC6-HSP90-mutp53 } \\
\text { complex) }\end{array}$ & $\begin{array}{l}\text { R175H, L194F, M237I, } \\
\text { R249S, R273H }\end{array}$ & $\mathrm{N} / \mathrm{A}$ & $\begin{array}{l}\text { SKBR3, T47D, SUM149, } \\
\text { Mahlavu, BT549, MDA-MB-468 }\end{array}$ & $\begin{array}{l}\text { Inhibition of the mevalonate-RhoA axis by cerivastatin or GGTI-298 reduces } \\
\text { HDAC6 activity, leading to HSP90 hyperacetylation and dissociation of HSP90 } \\
\text { from mutp53, which induces degradation of mutp53 by MDM2. }\end{array}$ & [51] \\
\hline HSP70/HSC70 & $\mathrm{R} 175 \mathrm{H}, \mathrm{R} 273 \mathrm{H}$ & N/A & MDA-MB-468, H1299 & $\begin{array}{l}\text { HSP70 selectively recognizes unfolded/misfolded TP53 proteins and } \\
\text { promotes its CHIP-dependent ubiquitination and degradation when HSP90 is } \\
\text { inhibited and mutp53 folding is blocked. }\end{array}$ & [96] \\
\hline HSP70 (not HSC70) & V143A, R175H & $\mathrm{N} / \mathrm{A}$ & $\begin{array}{l}\text { MDM2-/- TP53 } 3^{-/-} \text {MEFs, } \\
\text { H1299, SKBR3 }\end{array}$ & $\begin{array}{l}\text { HSP70 accelerates CHIP-mediated degradation of mutp53, whereas it partially } \\
\text { inhibits MDM2-mediated ubiquitination and degradation of mutp53 to } \\
\text { enhance nuclear aggregates which can be inhibited by HSC70. }\end{array}$ & [97] \\
\hline HSC70 & $\begin{array}{c}\text { R248Q, S241F, R158Inf, } \\
\text { R280L, G266Q, S227K, } \\
\text { S227R, E258K, A161T, } \\
\text { R273L, R273H, R280L, } \\
\text { R175H, R175D, R175C, } \\
\text { R248W, R248L, R282W, } \\
\text { P151H, P98S, G245C, } \\
\text { L194F }\end{array}$ & N/A & $\begin{array}{l}\text { OVCAR-3, ES2, SUM159, } \\
\text { MDA-MB-231, MDA-MB-435, } \\
\text { HCT116 }\end{array}$ & $\begin{array}{l}\text { Chaperone-mediated autophagy (CMA), which is induced in cells treated with } \\
\text { an autophagy inhibitor (spautin-1) under confluency or nutrient deprivation } \\
\text { conditions, facilitates nuclear export of mutp53 and promotes interaction of } \\
\text { mutp53 with HSC70, leading to mutp53 degradation through the lysosome. }\end{array}$ & [35] \\
\hline $\begin{array}{c}\text { Mortalin } \\
(\mathrm{mtHSP70/Grp75)}\end{array}$ & R249S & $\mathrm{N} / \mathrm{A}$ & $\mathrm{PLC} / \mathrm{PRF} / 5$ & $\begin{array}{l}\text { Mortalin knockdown induces nuclear translocation and apoptosis in a } \\
\text { mutp53-dependent manner. }\end{array}$ & [98] \\
\hline Tid/DNAJA3 (HSP40) & $\begin{array}{l}\text { R175H, L194F, R273H, } \\
\text { E285K }\end{array}$ & N/A & SKBR3, T47D, U373, BT474 & $\begin{array}{l}\text { Overexpression of Tid/DNAJA3 restores mitochondrial localization and } \\
\text { pro-apoptotic activities of TP53 in cells treated with desferroxamine (DFX). }\end{array}$ & [99] \\
\hline
\end{tabular}


Table 1. Cont

\begin{tabular}{|c|c|c|c|c|c|}
\hline Upstream Regulators & Mutant TP53 & $\begin{array}{c}\text { Modified } \\
\text { Amino Acids }\end{array}$ & Samples/Cell Lines & Outcomes/Effects & References \\
\hline \multicolumn{6}{|l|}{ Molecular Chaperons } \\
\hline DNAJB1 (HSP40) & $\mathrm{R} 175 \mathrm{H}$ & N/A & $\begin{array}{l}\text { H1299, CAL-33, HuCCT1, } \\
\text { FAMPAC, KLE, TOV112D }\end{array}$ & $\begin{array}{l}\text { Chetomin (CTM) binds to HSP40 and increases the interaction between HSP } 40 \\
\text { and R175H mutp53, leading to restoration of wtp53 activity and inhibition of } \\
\text { proliferation and tumor growth of multiple cancer cells expressing R175H } \\
\text { with upregulation of TP53 target genes. }\end{array}$ & [57] \\
\hline DNAJB1 (HSP40), HSP70 & $\begin{array}{l}\text { V143A, R158L, R175H, } \\
\text { Y220C, G245S, D281G, } \\
\text { R282W }\end{array}$ & N/A & H1299 & DNAJB1 and HSP70 facilitate binding of mutp53 to TAp73 $\alpha$. & [100] \\
\hline DNAJA1 (HSP40) & R156P, R175H, Y220C & $\mathrm{N} / \mathrm{A}$ & $\begin{array}{l}\text { KHOS/NP, SKBR3, CAL33, } \\
\text { BxPC3 }\end{array}$ & $\begin{array}{l}\text { DNAJA1 binds to and stabilizes mainly conformational or misfolded mutp } 53 \\
\text { by competitively binding to CHIP. }\end{array}$ & [29] \\
\hline BAG2 & $\begin{array}{l}\text { mouse R172H, R175H, } \\
\text { R248W, R273H }\end{array}$ & N/A & $\begin{array}{l}\text { R172H MEFs, H1299, Saos2, } \\
\text { HCT116 }\end{array}$ & $\begin{array}{l}\text { BAG2 binds to mutp53 (mouse R172H) and inhibits MDM2's activity to } \\
\text { accumulate mutp53, while BAG2 knockdown increases chemosensitivity and } \\
\text { reduces tumor growth and metastasis. }\end{array}$ & [101] \\
\hline BAG5 & $\begin{array}{l}\text { mouse R172H, R175H, } \\
\text { R248W, R273H }\end{array}$ & N/A & $\begin{array}{l}\text { R172H MEFs, H1299, Saos2, } \\
\text { HCT116 }\end{array}$ & $\begin{array}{l}\text { BAG5 binds to mutp53 (mouse R172H) and inhibits ubiquitination and } \\
\text { degradation of mutp53 by MDM2 and CHIP to accumulate mutp53 and } \\
\text { enhance mutp53 GOF, including cell proliferation, migration, chemoresistance, } \\
\text { and tumor growth. }\end{array}$ & [102] \\
\hline \multicolumn{6}{|l|}{ SNP } \\
\hline 72P/R polymorphism & V143A, V173L, R175H & $72 \mathrm{P}, 72 \mathrm{R}$ & Saos2 & $\begin{array}{l}\text { 72R-mutp53 binds more efficiently to TP73 to inactivate TP73-induced } \\
\text { apoptosis than 72P-mutp53. }\end{array}$ & [103] \\
\hline 72P/R polymorphism & $\begin{array}{l}\text { V173L, R175H, C176Y, } \\
\text { H179R, Y220C, C242Y, } \\
\text { G245S/D, R249S, R282W, } \\
\text { R273C }\end{array}$ & $72 \mathrm{P}, 72 \mathrm{R}$ & Saos2 & $\begin{array}{l}\text { 72R-mutp } 53 \text { shows higher efficiency on inhibition of apoptosis induced by } \\
\text { chemotherapy drugs, as compared to } 72 \mathrm{P} \text {-mutp } 53 \text {, mainly due to mutp53's } \\
\text { inhibitory binding with TP73. }\end{array}$ & [104] \\
\hline 72P/R polymorphism & R249S & $72 \mathrm{P}, 72 \mathrm{R}$ & H1299 & $\begin{array}{l}\text { Polymorphism at codon } 72 \text { in several TP53 mutants (R175H, G245S, R248W, } \\
\text { R249S, R273H, R282W) do not show any significant differences in resistance to } \\
\text { many chemotherapy drugs, whereas only } 72 \mathrm{R} \text { in R249S mutp53 makes cells } \\
\text { more resistance to doxorubicin than } 72 \mathrm{P} \text { in R249S. }\end{array}$ & [105] \\
\hline 72P/R polymorphism & $\mathrm{R} 175 \mathrm{H}, \mathrm{R} 273 \mathrm{H}$ & $72 \mathrm{P}, 72 \mathrm{R}$ & $\begin{array}{l}\text { H1299, PC13, HT29 } \\
\text { (72P-R273H), SW620 } \\
\text { (72R-R273H) }\end{array}$ & $\begin{array}{l}\text { 72R-mutp53 less efficiently binds to and inhibits activity of PCG- } 1 \alpha \text {, leading } \\
\text { to higher mitochondrial function and metastatic potential than } 72 \mathrm{P} \text {-mutp53. }\end{array}$ & [106] \\
\hline \multicolumn{6}{|l|}{ Dimer } \\
\hline $\begin{array}{l}\text { Mutations in the TP53 } \\
\text { oligomerization domain }\end{array}$ & R175H, R248W & E343K & U2OS, H1299 & $\begin{array}{l}\text { E343K mutation in mutp53 enhances degradation of mutp } 53 \text { by MDM2, } \\
\text { leading to inhibited migration. }\end{array}$ & [107] \\
\hline
\end{tabular}


The N-terminal serine residues of mutp53 are phosphorylated at multiple sites. Adorno et al. [73] show that activated Ras signaling in MDA-MB-231 cells promotes phosphorylation at S6 and S9 of mutp53 (R280K), promoting formation of a complex consisting of mutp53, Smad2, and TP63 to inhibit metastasis suppressor function of TP63.

Another well-studied phosphorylated serine residue at the N-terminus of mutp53 is S15, a key serine residue to activate wtp53 following genotoxic stress [108]. Melnikova et al. [109] find constitutive S15 phosphorylation in several TP53 mutants (V154A/R155C, H176Y, R270C, E283K) through ERK1/2 activation, using multiple UV-induced mouse skin tumors and their derived cell lines. In agreement, Song et al. [74] suggest that constitutively activated DNA damage signaling in mutp53-harboring tumors could account for stabilization of mutp53 via chronic S15 phosphorylation. However, Li et al. [94] show that several mutp53-carrying cell lines, including EB2, T47D, and DU145, lack constitutive phosphorylation of S15, although genotoxic stress induces the phosphorylation. Moreover, no correlation is found between S15 phosphorylation and the levels or localization of mutp53 in three breast cancer cell lines, HCC2157 (R248Q), MDA-MB-468 (R273H), and T47D (L194F) [110]. Intriguingly, Zerbini et al. [75] observe that inhibition of NF- $\mathrm{kB}$ by IкB overexpression in DU145 cells results in S15 phosphorylation of mutp53 (P223L/V274F) via GADD45 $\alpha$-mediated JNK1 activation, leading to potential restoration of wtp53 activity including increased p21 levels, DNA binding potential, and apoptosis. Conversely, Sugikawa et al. [111] show that a mutation at S15 or S315 to alanine in R175H mutp53 partially restores wtp53 function (apoptosis induction and DNA binding potential) in Saos2 osteosarcoma cells. Thus, phosphorylation of S15 in mutp53 may alter the structure or activity of mutp53, depending on cellular contexts or experimental conditions used.

Additionally, stathmin 1 (also known as oncoprotein 18 or metablastin) which plays a role in microtubule destabilization and dynamics contributes to mutp53 stability with phosphorylation at S15 and S37 [76]. Knockdown of stathmin 1 leads to reduced mutp53 stability, decreased BUB1 expression due to attenuated GOF activity, and inhibited viable cell proliferation, in multiple mutp53-expressing ovarian cancer cell lines including TOV112D (R175H) and MDAH-2774 (R273H). This is mainly due to stathmin 1's effects on enhancing interaction of mutp53 with DNA-PK, phosphorylation of mutp53 at S15 and S37 by DNA-PK, and mutp53 stabilization [76].

Besides S15, T18 and S46 are phosphorylated on wtp53, which is enhanced by PML [112-114]. PML also interacts with mutp53 (R175H, R273H, R273H/P309S) and is required for proliferation and colony formation of cancer cells bearing mutp53, suggesting that PML supports mutp53 GOF [77]. However, it remains unclear whether PML indeed promotes phosphorylation of mutp53 and which phosphorylation site induced by PML is required for enhanced proliferation and colony formation by mutp53.

S46 of wtp53 is known to be required for TP53-mediated apoptosis [115-117]. Peptidyl-prolyl cis/trans isomerase (PPIase, namely Pin1) isomerizes phospho-Serine/Threonine-Proline motifs, and Pin1-mediated isomerization of phosphorylated S46-P47 site in TP53 unleashes TP53's apoptotic potential upon DNA damage, by inducing its dissociation from the apoptosis inhibitor iASPP [118]. In mice carrying homozygous TP $53^{R 172 H}$ mutations, concomitant homozygous deletion of Pin1 attenuates tumor progression [78]. Pin1 also enhances migration and lung colonization of MDA-MB-231 cells in a manner dependent on mutp53. Moreover, Pin1 accelerates the inhibitory interaction of mutp53 with TP63, leading to inhibited metastasis suppressor function of TP63 and hence enhancing tumor aggressiveness [78]. Thus, in cells having wtp53 Pin1 supports TP53's tumor suppressor function by promoting apoptosis, while Pin1 enhances mutp53 GOF and tumor progression in cells expressing mutp53. It remains unclear whether observed phenotypes by Pin1 are mediated through its detection of phosphorylated S46-P47 site in mutp53.

C-terminal serine residues of mutp53 are also phosphorylated. Polo-like kinase 2 (PLK2), which is activated by DNA damage, phosphorylates mutp53 (R175H, R273H) at T377, leading to enhanced binding of mutp53 with p300, increased acetylation of mutp53, and induction of the GOF activity 
including increase in cell proliferation, NF-Y's transcriptional activity on cyclin A, cyclin B, cdk1, and cdc25C, and Adriamycin resistance [79].

Additionally, Matsumoto et al. [80] reveal S392 phosphorylation in over 50\% of TP53-positive (indicative of TP53 mutation; 90/137 tumors) esophageal squamous cell carcinomas (ESCCs) by immunohistochemistry. Importantly, phosphorylation of S392 is correlated with high levels of Ki67 staining, lymphatic invasion, and poor prognosis for patients with stage II and III advanced tumors. In their study, only three cases $(2.2 \%)$ show phosphorylation at S15. These results suggest that S392 phosphorylation in mutp53 may contribute to ESCC tumor progression $[70,80]$. It has also been proposed that $\mathrm{S} 392$ phosphorylation in mutp53 could enhance tetramer formation of mutp53, which may enhance hetero-oligomerization with wtp53 showing the dominant-negative effects (and likely GOF as well) and cell proliferation in aggressive urothelial transitional cell carcinomas (TCCs) [81]. To support this idea, Gillotin et al. [119] report that a non-phosphorylatable mutation at S392 (S392A) in $\mathrm{R} 175 \mathrm{H}$ mutp53 reduces the protein half-life. Intriguingly, S392A mutation does not affect the half-life of R248W mutp53 [119]. Moreover, Yap et al. [120] demonstrate that S392A mutation in two hotspot TP53 mutants (R175H and R248W) transforms rat embryonic fibroblasts in cooperation with Ha-Ras oncogene more potently than R175H and R248W TP53 mutants, suggesting that the non-phosphorylated form of mutp53 at S392 has increased oncogenic activity. Thus, the role of S392 phosphorylation in mutp53 stability and its oncogenic activity may be dependent on types of TP53 mutations and cellular contexts.

Overall, phosphorylation of wtp53 stabilizes and enhances the function of wtp53 as a transcription factor and a tumor suppressor. On the other hand, phosphorylation of mutp53 results in context-dependent changes in the stability and oncogenic GOF. Further detailed studies are needed to clarify the role of each phosphorylation site in mutp53 GOF.

\subsection{Acetylation}

CBP/p300, P/CAF (p300/CBP-associated factor), and Tip60 are well-documented acetyltransferases for wtp53 which enhance wtp53 transcriptional activity [121], while HDAC1 and SIRT1 deacetylate and inhibit the wtp53 function [122,123]. However, unlike wtp53, little is known about acetylation of mutp53 and the role in the mutp53 GOF activity.

Thirteen lysine (K) residues on wtp53 are reported to be acetylated. Three (K120, K164, K292) are in the DBD, two (K305, K320) are in the domain containing a nuclear localization signal (NLS), and eight (K351, K357, K370, K372, K373, K381, K382, K386) are located in the C-terminal regulatory domain including a tetramerization/oligomerization domain, a nuclear export signal (NES), and a negative regulatory domain (Figure 3) [124,125]. Notably, mutations in K120, K164, and K305 residues are found in human cancers [62]. Like wtp53, most of the lysine residues subject to acetylation in mutp 53 could also be modified by methylation, ubiquitination, SUMOylation, and neddylation; however, little is known about the roles of lysine methylation, SUMOylation, and neddylation in mutp53 GOF [62,124,125].

Minamoto et al. [72] report that mutp53 is hyperacetylated at K320, K373, and K382 in multiple cancer cells, including Hs578T breast cancer (V157F), U118MG glioblastoma (R213Q), DMS-92 small cell lung carcinoma (M237I), DLD1 colon adenocarcinoma (S241F), NCI-H596 lung adenocarcinoma (G245C), COLO320 colon adenocarcinoma (R248W), WiDr colon adenocarcinoma (R273H), HT-29 colon adenocarcinoma (R273H), ASPC-1 pancreatic adenocarcinoma (R273H), and Capan-2 pancreatic adenocarcinoma $(\mathrm{R} 273 \mathrm{H})$, as compared with acetylation on wtp53 in two fibroblast cell lines (GM00038, TIG). Warnock et al. [126] also show acetylation of K382 on R273H in multiple colon cancer cell lines (HT29, SW480, SW620). Recently, Jethwa et al. [82] have reported that TRRAP, a member of the phosphatidylinositol 3-kinase-related kinase (PIKK) family which is known to recruit histone acetyltransferases (HATs) to chromatin during transcription and DNA repair [127], increases the levels of multiple TP53 mutants through inhibition of the MDM2-proteasome axis in Burkitt lymphoma (BL-41: R248Q, BL-60: R248Q, CA-46: R248Q, DG-75: R283H/G245S, Namalwa: R248W, Raji: 
R213Q/Y234H, Ramos: I254D), diffuse large B-cell lymphoma (SUDHL-4: R273H), and colorectal cancer (Colo320: R248W) cell lines. Indeed, upon silencing of TRRAP, acetylation of mutp53 is significantly reduced. However, TRRAP knockdown induces arrest at G0/G1 phase of the cell cycle independent of TP53 status. Moreover, it remains unknown how much TRRAP contributes to mutp53 GOF activities in cancer. Nonetheless, these results support the idea that mutp53 acetylation plays a role in accumulation and oncogenic activity of mutp53 [60].

Intriguingly, Perez et al. [83] observe that exogenously expressed mutp53 (R175H, G245A, D281G) is acetylated at K320 and K373 by P/CAF upon treatment with TSA (trichostatin A), a deacetylase inhibitor, accompanied by increased apoptosis with enhanced DNA binding of mutp53 to the $p 21$ and PUMA promoters. Additionally, Knowell et al. [84] find that Id4-induced interaction between mutp53 and CBP/p300 results in increased acetylation at K320 and K373 on mutp53 (P223L/V274F), accompanied by apoptosis with upregulation of p21, BAX, and PUMA in DU145 cells. These results suggest the possibility that acetylation at K320 and K373 in mutp53 could alter the structure of mutp53 to restore wtp53 activity [128].

As mentioned in the previous section, glucose restriction triggers mutp53 degradation via autophagic cell death in several mutp53-carrying cancer cell lines, including TOV112D (R175H), MDA-MB-231 (R280K), T47D (L194F), BT-20 (K132Q), and PANC1 (R280T) [36]. Intriguingly, mutp53 (G245A) with acetylation-mimic (glutamine: Q) mutations at six lysine residues in K319, K320, K321, K370, K372, and K373 (referred to as G245A-K6Q) shows resistant to degradation and cell death induced by glucose restriction in $\mathrm{H} 1299$ cells, as compared with mutp53 (G245A). These results suggest that mutp53 stability is regulated by the level of glucose, and deacetylation at the C-terminal lysine residues is involved in the glucose restriction-mediated mutp53 degradation.

Moreover, Yi et al. [85] observe that deacetylation of mutp53 results in reduced levels and oncogenic activity of mutp53; YK-3-237, a small molecule compound which activates a deacetylase SIRT1, reduces acetylation of K382 of mutp53, using triple-negative breast cancer (TNBC) cell lines, BT549 (R249S), MDA-MB-468 (R273H), HS578T (V157F), and SUM149PT (M237I). This leads to reduced mutp53 level, induction of apoptotic cell death, and G2/M cell cycle arrest, with induction of wtp53 target genes (PUMA, NOXA), suggesting reactivation of wtp53 activity through deacetylation. In support of their findings, Zhang et al. [129] demonstrate that activated SIRT1 with phosphorylation at S47 serves as a prognostic factor for a longer relapse-free survival (RFS) in patients with hepatocellular carcinoma (HCC) carrying mutp53.

Thus, some lysine residues contribute to stabilization and activation of GOF mutp53, while other residues can alter the structure of mutp53 to restore wtp53 activity upon acetylation or deacetylation. Detailed analyses for each lysine residue in mutp53 are required to understand the exact role of mutp53 acetylation in its stabilization, GOF activity, and restoration of wtp53 activity.

\subsection{Ubiquitination}

Ubiquitination of mutp53 plays a crucial role in the stability and subcellular localization of mutp53, which impacts its GOF activities. Polyubiquitination of mutp53 leads to its degradation, while its monoubiquitination may alter subcellular localization of mutp53 likewise wtp53 [130,131]. There are many ubiquitin ligases and deubiquitinases that regulate ubiquitination of wtp53 to alter the stability, activity, and subcellular localization of wtp53, which is described in detail by other excellent review articles [132,133]. However, studies addressing ubiquitination of mutp53 are much less published as compared to those of wtp53.

Lukashchuk and Vousden [86] reveal that MDM2 retains the ability to interact with and induce degradation of mutp53 independently of the N-terminal interaction. However, some TP53 mutants including $\mathrm{R} 175 \mathrm{H}$ appear to be highly ubiquitinated by other ubiquitin ligases, such as COP1 (constitutively photomorphogenic 1) and CHIP, in tissue culture [86]. Additionally, they show that $\mathrm{R} 175 \mathrm{H}$ mutp53 is ubiquitinated, but not degraded, and localizes to the cytoplasm in MDM2 ${ }^{-/-} \mathrm{TP}^{-1-}$ cells, whereas $\mathrm{R} 273 \mathrm{H}$ mutp53 which is not ubiquitinated in the same cells is present in the nucleus [86]. 
Similarly, Nie et al. [87] observe that unfolded/misfolded mutp53 (detected by pAb240; C135Y, V143A, $\mathrm{H} 179 \mathrm{E}$ ) is more efficiently ubiquitinated and localizes to the cytoplasm to a greater extent than DNA contact mutp53 which retains wtp53 conformation (detected by pAb1620; R248W).

Recently, Frum et al. [88] report that phosphorylation of mutp53 (R273H) at S15 by ataxia-telangiectasia mutated (ATM) kinase following DNA damage results in monoubiquitination by MDM2, but not polyubiquitination, while ATM inhibition restores MDM2's ability to polyubiquitinate and degrade mutp53. These results suggest that G2M checkpoint activation of the cell cycle accumulates mutp53 by promoting monoubiquitination by MDM2, rather than polyubiquitination [88].

MDM2 has more than 40 splice variants, but it is unclear whether all variants are translated and have functional effects on TP53 [134]. Several spliced isoforms, such as isoform A, B, and C, are detected and co-expressed with full-length MDM2 (MDM2-FL) in tumors. MDM2 isoform B (MDM2-B) is one of the most studied isoforms lacking the TP53-binding domain but retaining the C-terminal domain to interact with MDM2-FL [135-137]. Zheng et al. [89] demonstrate that MDM2-B promotes mutp53 accumulation in multiple human cancer cell lines endogenously or exogenously expressing R175H, R248W, R273H, Y220C, and S241F. This accumulation is caused by MDM2-B's ability to bind with and inhibit MDM2-FL which mediates mutp53 degradation. Using TP53 ${ }^{\text {R248W/- }}$ HCT116 cells, they also show that MDM2-B enhances mutp53 GOF including tumor growth and metastasis in vivo. Additionally, MDM2-B is overexpressed in TP53 ${ }^{R 172 H / R 172 H}$ mouse lymphomas. Thus, it is postulated that any proteins which inhibit MDM2 activity could stabilize mutp53 to increase the GOF activities.

CHIP is a cofactor that interacts with HSC70 and accelerates ubiquitin-dependent degradation of chaperone substrates through its carboxyl-terminal U-box [138]. Mutp53 (R175H) degradation by CHIP is shown by Esser et al. [139]. HSP90 inhibition also induces CHIP-mediated degradation of mutp53 [94]. Our group has recently demonstrated that cholesterol-lowering drugs, "statins," inhibit binding between conformational/misfolded mutp53 (R156P, R175H, Y220C) and DNAJA1, a member of HSP40, leading to CHIP-mediated nuclear export and degradation of mutp53 [29]. Intriguingly, knockdown of DNAJA1 or mevalonate kinase also induces CHIP-mediated ubiquitination and degradation of mainly conformational/misfolded mutp53, similarly to statin treatment [29]. Moreover, Maan et al. [30] report that CHIP induces ubiquitination and degradation of aggregating TP53 mutants (R110P, R175H), but not non-aggregating mutants (R248W, R273H), both in normoxia and hypoxia. The observed ubiquitination and degradation of aggregating TP53 mutants by CHIP are mediated via K63-linked polyubiquitination and are dependent on autophagy [30]. These results may suggest that CHIP mainly targets unfolded/misfolded aggregating TP53 mutants for degradation.

Another ubiquitin ligase which can ubiquitinate and degrade wtp53 is Pirh2. Intriguingly, arsenic trioxide (ATO) induces Pirh2-mediated degradation of multiple TP53 mutants in SW480 (R273H), MiaPaCa-2 (R248W), HaCaT (H179Y/R282W) cells, as well as HCT116 cells expressing R175H and $\mathrm{R} 273 \mathrm{H}[90]$.

In summary, mutp53 is ubiquitinated by MDM2 and other ubiquitin ligases. Unfolded/misfolded mutp53 may be ubiquitinated by multiple ubiquitin ligases such as MDM2 and CHIP, while ubiquitination of DNA contact mutp53 is mainly executed by MDM2. Additionally, ubiquitinated mutp53 appears be exported to the cytoplasm for degradation likewise wtp53. Thus, ubiquitination and degradation of mutp53 may be dependent on its binding to molecular chaperones and their associated ubiquitin ligases.

Deubiquitinases (DUBs) are a group of proteases that cleave ubiquitin from proteins. USP10 is a cytoplasmic ubiquitin-specific protease and is shown to deubiquitinate wtp53 to reverse MDM2-induced wtp53 ubiquitination, nuclear export, and degradation [91]. Knockdown of USP10 results in reduction in wtp53 levels and wtp53-mediated apoptosis. This group also addresses the question of whether USP10 acts on mutp53. USP10 levels are positively correlated with mutp53 in renal cell carcinoma (RCC) tissues; USP10 is overexpressed in RCC having mutp53, whereas USP10 levels are undetectable in RCC tissues with wtp53. In the 786-O RCC cell line, USP10 overexpression inhibits MDM2-mediated mutp53 ubiquitination leading to stabilization of mutp53, while USP10 
downregulation increases mutp53 ubiquitination to decrease its stability. Furthermore, overexpression of USP10 in 786-O cells increases levels of mutp53, leading to enhanced colony formation and proliferation, which is nullified by depletion of mutp53. Thus, increased USP10 levels would be beneficial to progression of cancer carrying mutp53, whereas in cancer cells with wtp53 USP10 acts as a tumor suppressor [91]. However, it is unclear whether USP10 antagonizes ubiquitination of mutp53 by other ubiquitin ligases, USP10 alters subcellular localization of mutp53, and USP10 plays a role in deubiquitination of different TP53 mutants.

USP15 is another deubiquitinase that is reported to increase the stability of MDM2 and hence reduce wtp53 activity to inhibit apoptosis in cancer cells [140]. However, Padmanabhan et al. [92] have recently shown that MCB-613, a small molecule stimulator of steroid receptor coactivators (SRCs), enhances nuclear export, ubiquitination, and lysosome-mediated degradation of $\mathrm{R} 175 \mathrm{H}$ mutp53, but not $\mathrm{R} 273 \mathrm{H}$, through depletion of USP15 protein via a post-translational mechanism independent of MDM2, leading to reduced viability of ovarian cancer cells carrying R175H (TYK-Nu, TOV112D). A DUB inhibitor (NSC632839) and USP15 knockdown phenocopies biological effects of MCB-613. However, it remains unclear why only $\mathrm{R} 175 \mathrm{H}$, but not $\mathrm{R} 273 \mathrm{H}$, is degraded by USP15 depletion and how exactly MCB-613 reduces USP15 levels independent of SRC stimulation.

Thus, several ubiquitin ligases and deubiquitinases can regulate ubiquitination and degradation of both wtp53 and mutp53; however, it remains unclear whether a ubiquitin ligase which ubiquitinates both wtp53 and mutp53 modifies the same lysine residues, if different ubiquitin ligases modify the same lysine residues, and which lysine residues are involved in subcellular localization of mutp53. It is also unknown if other ubiquitin-like modifications such as neddylation and SUMOylation occur in mutp53 and whether these modifications alter the stability, GOF activities, and subcellular localization of mutp53.

\section{Molecular Chaperones}

Endogenous and environmental stresses, such as heat shock, oxidative stress, inflammation, infection, chemicals, and irradiation, significantly impact behavior of the cell. Heat shock proteins (HSPs) play central roles in responding to these stresses as molecular chaperones. Molecular chaperones interact with a variety of proteins to promote their proper folding in order to prevent generation of unfolded/misfolded or damaged proteins, causing them to be refolded or degraded [141].

HSP family proteins, including HSP90, HSP70 (DnaK homologue), and HSP40 (DnaJ homologue), play major roles in protein folding, protein maturation, protein localization, proteolysis, and cell signaling [141]. There are many studies documenting physical and functional interactions of HSP90 and HSP70 with wtp53 [93,142-144]. HSPs are also known to bind with mutp53 to refold, stabilize, or degrade it [93,144-148].

HSP90 plays a crucial role in stabilizing mutp53. Geldanamycin, a HSP90 inhibitor, alters the physical association of mutp53 with the HSP90 complex, leading to reduced protein half-life of several TP53 mutants via ubiquitination and proteasomal degradation, in multiple cancer cell lines, including T47D (L194F), MDA-MB-468 (R273H), and SKBR3 (R175H) [149-151]. HSP90 is shown to form a complex with MDM2 and mutp53 (L194F, S241F, R273C, R273H) to block ubiquitination of both MDM2 and mutp53, while geldanamycin induces MDM2-mediated mutp53 degradation [93]. Moreover, Li et al. [94] demonstrate that HSP90 forms a complex with mutp53 to prevent mutp53's aggregation by inhibiting the E3 ligase activity of MDM2 and CHIP in multiple cancer cells, including MDA-MB-468 (R273H), MDA-MB-231 (R280K), DU145 (P223L/V274F), T47D (L194F), SW480 (R273H/P309S), SKBR3 (R175H), and 5637 (R280T). Additionally, Li et al. [95] report that SAHA (suberoylanilide hydroxamic acid), a HDACi, causes cell death preferentially in cancer cells carrying mutp53 (SW480, DU145, T47D, MDA-MB-231, ES2, and SKBR3) and sensitizes MDA-MB-231 and T47D cells to a chemotherapy agent, Camptothesin. This is due to degradation of mutp53 by SAHA, which is likely caused by hyperacetylation and inhibition of HSP90 through inactivation of HDAC6 by SAHA [152]. Thus, SAHA ultimately inhibits HSP90 activity, releasing mutp53 from the HDAC6-HSP90-mutp53 complex, 
enabling mutp53 degradation by MDM2 and CHIP [95]. Importantly, in vivo evidence showing that cancer cells are addicted to mutp53 is provided by Alexandrova et al. [50], using HSP90 inhibitors; pharmacological inhibition of HSP90 by ganetespib results in degradation of mutp53 in lymphomas and prolongs survival of $T P 53^{R 172 H / R 172 H}$ and $T P 53^{R 248 Q /-}$ mice with minimal effects on TP53-null mice. Recently, Ingallina et al. [51] observed that stiffness in the extracellular matrix stimulates RhoA-dependent remodeling of filamentous actin and actomyosin contractility which can accumulate mutp53 (V157F, M273I, R280K, mouse R172H) through the HDAC6-HSP90 axis. Thus, inhibition of RhoA activity through inhibition of the mevalonate-RhoA axis by an HMG-CoA-R inhibitor (cerivastatin) or an inhibitor of geranylgeranyltransferase type I (GGTI-298) reduces HDAC6 activity and hence induces hyperacetylation of HSP90, leading to dissociation of mutp53 from HSP90 and degradation of mutp53 by MDM2 (R175H, L194F, M237I, R249S, R273H).

HSP70 is another chaperone which is involved in mutp53 stabilization or degradation. Muller et al. [96] show that HSP70/HSC70 (heat-shock cognate protein of $70 \mathrm{kDa}$ ) selectively recognizes unfolded/misfolded TP53 proteins and promotes its CHIP-dependent ubiquitination and degradation when HSP90 activity is inhibited and hence mutp53 folding is blocked (R175H, R273H). On the other hand, Wiech et al. [97] observe that HSP70, whose levels are commonly high in cancers, accelerates CHIP-mediated degradation of mutp53 (R175H), whereas HSP70 partially inhibits MDM2-mediated ubiquitination and degradation of exogenous mutp53 (V143A, R175H) to enhance formation of nuclear aggregates. Intriguingly, HSC70 inhibits the process of nuclear aggregation of mutp53, suggesting that the mechanism of HSP70 activity towards mutp53 could be different from that of HSC70. Moreover, Vakifahmetoglu-Norberg et al. [35] reveal that mutp53, but not wtp53, binds to a cytosolic HSC70 when ES2 (S241F) cells are treated with spautin-1, a small molecule inhibitor of autophagy, under confluency or nutrient deprivation conditions. This experimental condition induces chaperone-mediated autophagy (CMA) which facilitates nuclear export of mutp53 and promotes interaction of mutp53 with HSC70, leading to mutp53 degradation through the lysosome. However, Finlay et al. find that conformational mutp53 preferentially binds to HSC70, but this HSC70-mutp53 complex increases the protein half-life of mutp53 [153]. Such inconsistent roles of HSP70 and HSC70 in mutp53 stability may be dependent on cellular context or experimental settings.

Mortalin is a member of mitochondrial HSP70 and is also known as mtHSP70/Grp75 (mot-2). Mortalin is involved in mitochondrial biogenesis regulating mitochondrial import of nuclear-encoded proteins [154]. Mortalin is also shown to sequester wtp53 to the cytoplasm [155]. Recently, Lu et al. [98] reported that mortalin binds to mutp53, and knockdown of mortalin results in nuclear translocation of mutp53 and apoptosis in an HCC cell line, PLC/PRF/5. This is not observed in MIHA and HepG2 (wtp53) cell lines, and apoptosis induced by mortalin knockdown is nullified by a TP53 inhibitor (PFT- $\mu$ ) or knockdown of mutp53. These results suggest that mortalin-knockdown-mediated apoptosis is dependent on mutp53 [98]. However, detailed mechanisms including whether mortalin knockdown restores structure and activity of wtp53 remain unclear.

HSP40 is another chaperone that binds with conformational or misfolded mutp53 (R175H) [156]. Mass spectrometry analyses also support binding of multiple HSP40 members with mutp53 $[146,156]$. Tid1/DNAJA3 is the tumor suppressor and forms a complex with wtp53 under hypoxia induced by an iron chelator desferroxamine (DFX), which causes wtp53 translocation to the mitochondria and apoptosis $[99,157]$. In multiple glioma and breast cancer cells carrying mutp53, including U373 (R273H), T47D (L194F), SKBR3 (R175H), and BT474 (E285K), overexpression of Tid/DNAJA3 restores mitochondrial localization and pro-apoptotic activities of TP53 when these cells are treated with DFX [99]. Additionally, Hiraki et al. [57] identify HSP40, specifically DNAJB1, as a factor that contributes to restoring TP53 activity of mutp53 (R175H) when cells are treated with chetomin (CTM), through a cell-based, high-throughput small molecule screen. CTM binds to HSP40 and increases the interaction between HSP40 and R175H mutp53, leading to restoration of wtp53 activity. Indeed, CTM specifically inhibits proliferation and tumor growth of multiple cancer cells expressing R175H mutp53 with upregulation of TP53 target genes including p21, PUMA, and MDM2, as well as mutp53's 
binding to the TP53-resposible elements of these genes. Moreover, CTM restores MDM2's ability to induce mutp53 degradation. Additionally, Tracz-Gaszewska et al. [100] observe that DNAJB1 and HSP70 facilitate binding of mutp53 (V143A, R158L, R175H, Y220C, G245S, D281G, R282W) to TAp73 $\alpha$. Another HSP40 member that plays a role in stabilization of mutp53 is DNAJA1. Our group reveals that DNAJA1 binds to and stabilizes mainly conformational or misfolded mutp53 (R156P, R175H, Y220C) by competitively binding to CHIP ubiquitin ligase [29]. Intriguingly, statins inhibit the mutp53-DNAJA1 binding to induce degradation of conformational/misfolded mutp53 by CHIP [29].

BCL2-associated athanogene (BAG) family proteins are co-chaperones that interact with mutp53. Through mass spectrometry analyses, two BAG family proteins, BAG2 and BAG5, are found to bind with mutp53 (mouse R172H) and promote its GOF activity [101,102]. Yue et al. [101] show that BAG2 binds to mouse R172H mutp53 in mouse embryonic fibroblasts (MEFs) and multiple human cell lines including TP53 ${ }^{R 248 \mathrm{~W} /}$ - HCT116 cells as well as H1299 and Saos2 cells exogenously expressing $\mathrm{R} 175 \mathrm{H}, \mathrm{R} 248 \mathrm{~W}$, and R273H mutp53. They observe that BAG2 inhibits MDM2's activity on mutp53 and accumulate the protein levels of mutp53. Furthermore, BAG2 knockdown enhances sensitivity of mutp53-expressing cells to 5-Fluorouracil, a chemotherapy drug, and reduces migration, tumor growth, and lung colonization of TP53 ${ }^{R 248 \mathrm{~W} /}-\mathrm{HCT} 116$ cells. Moreover, BAG2 is elevated in a diverse range of human cancers, including colorectal cancers, lung cancers, breast cancers and sarcomas, while high levels of BAG2 are associated with increased mutp53 levels and poor prognosis in these cancer patients [101]. Later, the same group also found that another BAG member, BAG5, interacts with several mutp53 (R175H, R248W, R273H, mouse R172H) to inhibit ubiquitination and degradation of mutp53 by MDM2 and CHIP E3 ubiquitin ligases [102]. This interaction results in mutp53 accumulation and enhanced GOF activities including cell proliferation, migration, chemoresistance, and tumor growth. Interestingly, BAG5 cooperates with BAG2 on cell migration and chemoresistance. Similar to BAG2, BAG5 is overexpressed in many human tumors (colorectal cancers, lung cancers, breast cancers and skin) with a positive correlation with poor prognosis of breast cancer patients [102].

Thus, multiple chaperone and co-chaperone proteins play crucial roles in mutp53 stability and GOF activities as well as restoration of wtp53 structure and activity. Currently, only HSP90 inhibitors are in clinical trials for cancer therapy. Development of inhibitors for other HSPs and chaperones/co-chaperones would greatly help understand mechanisms behind restoration of wtp53 activity and mutp53 stabilization/GOF and may also advance current therapeutic strategies for cancers carrying mutp53.

\section{SNP at Codon 72 in Mutp53}

A SNP in wtp53 at codon 72 alters localization and function of wtp53, where arginine 72 (72R)-wtp53 has greater ability to localize to the mitochondria and induce apoptosis more efficiently than proline 72 (72P)-wtp53 [158]. Evidence indicates that SNP72 in mutp53 also affects the GOF activity. Marin et al. [103] show that several TP53 mutants (V143A, V173L, R175H) carrying 72R polymorphism (72R-mutp53) more efficiently bind to TP73 to inactivate TP73-induced apoptosis than those carrying 72P (72P-mutp53) using exogenously overexpressed TP53 mutants in Saos2 cells. Similarly, Bergamaschi et al. [104] find that many 72R-mutp53, including V173L, R175H, C176Y, H179R, Y220C, C242Y, G245S/D, R249S, R282W, and R273C, show higher efficiency on inhibition of apoptosis induced by chemotherapy drugs (cisplatin, Taxol, doxorubicin), as compared to 72P-mutp53. This is mainly caused by inhibitory binding of mutp53 with TP73. Interestingly, SNP72 in some mutp53, including P142L, P152Q, R158G, and A161V, has minimal impact on cisplatin-induced apoptosis [104]. Although several studies observe that mutp53 (R175, Y220C, R248W, D281G) efficiently interacts with TP73, direct comparison of binding affinity to TP73 is not made between 72P- and 72R-mutp53 [159-162]. Vikhanskaya et al. [105] also show that 72R polymorphism in several TP53 mutants (R175H, G245S, R248W, R249S, R273H, R282W) does not show any significant differences in resistance to many chemotherapy drugs, including cisplatin, etoposide, gemcitabine, vinblastine, and Taxol, when compared with 72P-mutp53. Only the cells expressing 72R-R249S show more resistance to 
doxorubicin than those with 72P-R249S. Differences among these studies could be due to differences of cell types or experimental conditions used.

Recently, Basu et al. [106] reported that 72R-mutp53 (R175H, R273H) shows higher invasive and metastatic potential than those with 72P-mutp53, by overexpressing 72P- or 72R-mutp53 in TP53-null H1299 or PC3 cells, as well as by comparing results between two colon cancer cell lines, HT29 (72P-R273H) and SW620 (72R-R273H). They reveal that 72P-mutp53 more efficiently binds to and inhibits activity of PCG- $1 \alpha$, a master regulator of mitochondrial function, as compared with 72R-mutp53. As a result, cancer cells carrying 72R-mutp53 have increased mitochondrial function, leading to enhanced metastatic capacity. Moreover, 72R-mutp53 is correlated with poorer outcomes in human breast cancer, as compared with 72P-mutp53 [106]. Further studies, specifically in vivo studies using genetically engineered Hupki (human TP53 knockin) mouse models in combination with TP53 mutations, are required to obtain the physiological role of SNP72 of each TP53 mutant in mutp53 GOF and tumor progression $[163,164]$.

\section{Dimer-Forming Mutp53}

Oligomerization of TP53 has been implicated in TP53's DNA binding/transcriptional activity, ubiquitination/degradation, and interactions with TP53 binding partners [165]. Recently, Prives's group has shown that the $\mathrm{N}$-terminal domain of MDM2 binds to the C-terminal domain of dimer-forming TP53 in which a mutation is inserted in the TP53 oligomerization domain $(\mathrm{E} 343 \mathrm{~A} / \mathrm{K}$, L344A, L347T, E348A), leading to TP53 degradation [107]. Additionally, the dimer-forming TP53 is prone to MDM2-mediated nuclear export. The dimer-forming TP53 is partially unfolded and is degraded through ubiquitin-independent degradation by the $20 \mathrm{~S}$ proteasome, but not $26 \mathrm{~S}$ proteasome. Moreover, E343K mutation in two hotspot R175H and R248W mutp53 results in enhanced degradation of mutp53 by MDM2. Biologically, E343K mutation in R175H mutp53 leads to reduced R175H-mediated migration of H1299 cells [107]. This study may provide novel opportunities of targeting mutp53 to cancer therapy. Further studies required include clarification of in vivo physiological roles of dimer-forming TP53 in tumor progression using animal models, elucidation of the roles of naturally occurring TP53 mutations in the oligomerization domain in dimer formation, and identification of signals which impact oligomerization of mutp53.

\section{Conclusions}

This article has summarized multiple factors that impact levels, subcellular localization, and GOF activities of mutp53, as well as those inducing reactivation of wtp53 or depletion of mutp53. These include the upstream regulators of mutp53, such as genotoxic stress, PTMs, ubiquitin ligases, and molecular chaperones, as well as different sequences in mutp53 including codon 72 polymorphism and mutations in the oligomerization domain. Although studies examining upstream regulators of mutp53 GOF activities are limited, unlike wtp53, many upstream regulators of wtp53 also appear to impact mutp53 stability and GOF. However, the biological consequences are distinct between wtp53 and mutp53, which can be dependent on types of TP53 mutations, cellular context, and experimental conditions. To clarify these differences, detailed studies using various TP53 mutants in a well-controlled experimental setting should be performed in the future.

In conclusion, stability and activity of mutp53 are altered by multiple factors, some of which regulate wtp53 activity. However, the biological consequences are distinct. More studies are required to obtain clear-cut conclusion of the roles of mutp53 PTMs and SNPs in the GOF activity and cancer progression.

Author Contributions: S.Y. summarized and organized literatures, while S.Y. and T.I. wrote the manuscript.

Funding: This manuscript is supported by NIH R01 CA174735 (TI), R01 CA214916 (TI), and Bradon's Hope (TI) grants. 
Acknowledgments: We thank Mohamed Alalem, Atul Ranjan, and Elizabeth Thoenen for editing the manuscript and helpful discussion.

Conflicts of Interest: The authors declare no conflict of interest.

\section{References}

1. Vogelstein, B.; Lane, D.; Levine, A.J. Surfing the p53 network. Nature 2000, 408, 307-310. [CrossRef] [PubMed]

2. Kruiswijk, F.; Labuschagne, C.F.; Vousden, K.H. p53 in survival, death and metabolic health: A lifeguard with a licence to kill. Nat. Rev. Mol. Cell Biol. 2015, 16, 393-405. [CrossRef] [PubMed]

3. Baugh, E.H.; Ke, H.; Levine, A.J.; Bonneau, R.A.; Chan, C.S. Why are there hotspot mutations in the TP53 gene in human cancers? Cell Death Differ. 2018, 25, 154-160. [CrossRef] [PubMed]

4. Soussi, T.; Beroud, C. Assessing TP53 status in human tumours to evaluate clinical outcome. Nat. Rev. Cancer 2001, 1, 233-240. [CrossRef]

5. Powell, B.; Soong, R.; Iacopetta, B.; Seshadri, R.; Smith, D.R. Prognostic significance of mutations to different structural and functional regions of the p53 gene in breast cancer. Clin. Cancer Res. 2000, 6, 443-451. [PubMed]

6. Muller, P.A.; Vousden, K.H. Mutant p53 in cancer: New functions and therapeutic opportunities. Cancer Cell 2014, 25, 304-317. [CrossRef] [PubMed]

7. Parrales, A.; Iwakuma, T. p53 as a Regulator of Lipid Metabolism in Cancer. Int. J. Mol. Sci. $2016,17$. [CrossRef] [PubMed]

8. Dittmer, D.; Pati, S.; Zambetti, G.; Chu, S.; Teresky, A.K.; Moore, M.; Finlay, C.; Levine, A.J. Gain of function mutations in p53. Nat. Genet. 1993, 4, 42-46. [CrossRef]

9. Kern, S.E.; Kinzler, K.W.; Baker, S.J.; Nigro, J.M.; Rotter, V.; Levine, A.J.; Friedman, P.; Prives, C.; Vogelstein, B. Mutant p53 proteins bind DNA abnormally in vitro. Oncogene 1991, 6, 131-136.

10. Brazdova, M.; Navratilova, L.; Tichy, V.; Nemcova, K.; Lexa, M.; Hrstka, R.; Pecinka, P.; Adamik, M.; Vojtesek, B.; Palecek, E.; et al. Preferential binding of hot spot mutant p53 proteins to supercoiled DNA in vitro and in cells. PLOS ONE 2013, 8, e59567. [CrossRef]

11. Adhikari, A.S.; Iwakuma, T. Mutant p53 gain of oncogenic function: In vivo evidence, mechanism of action and its clinical implications. Fukuoka Igaku Zasshi 2009, 100, 217-228.

12. Kim, M.P.; Lozano, G. Mutant p53 partners in crime. Cell Death Differ. 2018, 25, 161-168. [CrossRef]

13. Sabapathy, K. The Contrived Mutant p53 Oncogene-Beyond Loss of Functions. Front. Oncol. 2015, 5, 276. [CrossRef]

14. Stambolsky, P.; Tabach, Y.; Fontemaggi, G.; Weisz, L.; Maor-Aloni, R.; Siegfried, Z.; Shiff, I.; Kogan, I.; Shay, M.; Kalo, E.; et al. Modulation of the vitamin D3 response by cancer-associated mutant p53. Cancer Cell 2010, 17, 273-285. [CrossRef]

15. Kim, M.P.; Zhang, Y.; Lozano, G. Mutant p53: Multiple Mechanisms Define Biologic Activity in Cancer. Front. Oncol. 2015, 5, 249. [CrossRef]

16. Goh, A.M.; Coffill, C.R.; Lane, D.P. The role of mutant p53 in human cancer. J. Pathol. 2011, 223, $116-126$. [CrossRef]

17. Gualberto, A.; Aldape, K.; Kozakiewicz, K.; Tlsty, T.D. An oncogenic form of p53 confers a dominant, gain-of-function phenotype that disrupts spindle checkpoint control. Proc. Natl. Acad. Sci. USA 1998, 95, 5166-5171. [CrossRef]

18. Blandino, G.; Levine, A.J.; Oren, M. Mutant p53 gain of function: Differential effects of different p53 mutants on resistance of cultured cells to chemotherapy. Oncogene 1999, 18, 477-485. [CrossRef]

19. Weisz, L.; Oren, M.; Rotter, V. Transcription regulation by mutant p53. Oncogene 2007, 26, $2202-2211$. [CrossRef]

20. Di Agostino, S.; Strano, S.; Emiliozzi, V.; Zerbini, V.; Mottolese, M.; Sacchi, A.; Blandino, G.; Piaggio, G. Gain of function of mutant p53: The mutant p53/NF-Y protein complex reveals an aberrant transcriptional mechanism of cell cycle regulation. Cancer Cell 2006, 10, 191-202. [CrossRef]

21. Zalcenstein, A.; Stambolsky, P.; Weisz, L.; Muller, M.; Wallach, D.; Goncharov, T.M.; Krammer, P.H.; Rotter, V.; Oren, M. Mutant p53 gain of function: Repression of CD95(Fas/APO-1) gene expression by tumor-associated p53 mutants. Oncogene 2003, 22, 5667-5676. [CrossRef] 
22. Lang, G.A.; Iwakuma, T.; Suh, Y.A.; Liu, G.; Rao, V.A.; Parant, J.M.; Valentin-Vega, Y.A.; Terzian, T.; Caldwell, L.C.; Strong, L.C.; et al. Gain of function of a p53 hot spot mutation in a mouse model of Li-Fraumeni syndrome. Cell 2004, 119, 861-872. [CrossRef]

23. Terzian, T.; Suh, Y.A.; Iwakuma, T.; Post, S.M.; Neumann, M.; Lang, G.A.; Van Pelt, C.S.; Lozano, G. The inherent instability of mutant p53 is alleviated by Mdm2 or p16INK4a loss. Genes Dev. 2008, 22, 1337-1344. [CrossRef]

24. Iwakuma, T.; Lozano, G.; Flores, E.R. Li-Fraumeni syndrome: A p53 family affair. Cell Cycle 2005, 4, 865-867. [CrossRef]

25. Suh, Y.A.; Post, S.M.; Elizondo-Fraire, A.C.; Maccio, D.R.; Jackson, J.G.; El-Naggar, A.K.; Van Pelt, C.; Terzian, T.; Lozano, G. Multiple stress signals activate mutant p53 in vivo. Cancer Res. 2011, 71, 7168-7175. [CrossRef]

26. Joerger, A.C.; Fersht, A.R. Structural biology of the tumor suppressor p53 and cancer-associated mutants. Adv. Cancer Res. 2007, 97, 1-23. [CrossRef]

27. Joerger, A.C.; Fersht, A.R. Structural biology of the tumor suppressor p53. Annu. Rev. Biochem. 2008, 77, 557-582. [CrossRef]

28. Jenkins, J.R.; Rudge, K.; Chumakov, P.; Currie, G.A. The cellular oncogene p53 can be activated by mutagenesis. Nature 1985, 317, 816-818. [CrossRef]

29. Parrales, A.; Ranjan, A.; Iyer, S.V.; Padhye, S.; Weir, S.J.; Roy, A.; Iwakuma, T. DNAJA1 controls the fate of misfolded mutant p53 through the mevalonate pathway. Nat. Cell Biol. 2016, 18, 1233-1243. [CrossRef]

30. Maan, M.; Pati, U. CHIP promotes autophagy-mediated degradation of aggregating mutant p53 in hypoxic conditions. FEBS J. 2018. [CrossRef]

31. Olive, K.P.; Tuveson, D.A.; Ruhe, Z.C.; Yin, B.; Willis, N.A.; Bronson, R.T.; Crowley, D.; Jacks, T. Mutant p53 gain of function in two mouse models of Li-Fraumeni syndrome. Cell 2004, 119, 847-860. [CrossRef]

32. Dibra, D.; Mitra, A.; Newman, M.; Xia, X.; Cutrera, J.J.; Gagea, M.; Kleinerman, E.S.; Lozano, G.; Li, S. Lack of Immunomodulatory Interleukin-27 Enhances Oncogenic Properties of Mutant p53 In Vivo. Clin. Cancer Res. 2016, 22, 3876-3883. [CrossRef]

33. Haupt, S.; Mitchell, C.; Corneille, V.; Shortt, J.; Fox, S.; Pandolfi, P.P.; Castillo-Martin, M.; Bonal, D.M.; Cordon-Cardo, C.; Lozano, G.; et al. Loss of PML cooperates with mutant p53 to drive more aggressive cancers in a gender-dependent manner. Cell Cycle 2013, 12, 1722-1731. [CrossRef]

34. Yallowitz, A.R.; Li, D.; Lobko, A.; Mott, D.; Nemajerova, A.; Marchenko, N. Mutant p53 Amplifies Epidermal Growth Factor Receptor Family Signaling to Promote Mammary Tumorigenesis. Mol. Cancer Res. MCR 2015, 13, 743-754. [CrossRef]

35. Vakifahmetoglu-Norberg, H.; Kim, M.; Xia, H.G.; Iwanicki, M.P.; Ofengeim, D.; Coloff, J.L.; Pan, L.; Ince, T.A.; Kroemer, G.; Brugge, J.S.; et al. Chaperone-mediated autophagy degrades mutant p53. Genes Dev. 2013, 27, 1718-1730. [CrossRef]

36. Rodriguez, O.C.; Choudhury, S.; Kolukula, V.; Vietsch, E.E.; Catania, J.; Preet, A.; Reynoso, K.; Bargonetti, J.; Wellstein, A.; Albanese, C.; et al. Dietary downregulation of mutant p53 levels via glucose restriction: Mechanisms and implications for tumor therapy. Cell Cycle 2012, 11, 4436-4446. [CrossRef]

37. Choudhury, S.; Kolukula, V.K.; Preet, A.; Albanese, C.; Avantaggiati, M.L. Dissecting the pathways that destabilize mutant p53: The proteasome or autophagy? Cell Cycle 2013, 12, 1022-1029. [CrossRef]

38. Halasi, M.; Pandit, B.; Gartel, A.L. Proteasome inhibitors suppress the protein expression of mutant p53. Cell Cycle 2014, 13, 3202-3206. [CrossRef]

39. Parrales, A.; Iwakuma, T. Targeting Oncogenic Mutant p53 for Cancer Therapy. Front. Oncol. 2015, 5, 288. [CrossRef]

40. Jung, C.L.; Mun, H.; Jo, S.Y.; Oh, J.H.; Lee, C.; Choi, E.K.; Jang, S.J.; Suh, Y.A. Suppression of gain-of-function mutant p53 with metabolic inhibitors reduces tumor growth in vivo. Oncotarget 2016, 7, 77664-77682. [CrossRef]

41. Hientz, K.; Mohr, A.; Bhakta-Guha, D.; Efferth, T. The role of p53 in cancer drug resistance and targeted chemotherapy. Oncotarget 2017, 8, 8921-8946. [CrossRef] [PubMed]

42. Boeckler, F.M.; Joerger, A.C.; Jaggi, G.; Rutherford, T.J.; Veprintsev, D.B.; Fersht, A.R. Targeted rescue of a destabilized mutant of p53 by an in silico screened drug. Proc. Natl. Acad. Sci. USA 2008, 105, 10360-10365. [CrossRef] [PubMed] 
43. Flores, E.R.; Tsai, K.Y.; Crowley, D.; Sengupta, S.; Yang, A.; McKeon, F.; Jacks, T. p63 and p73 are required for p53-dependent apoptosis in response to DNA damage. Nature 2002, 416, 560-564. [CrossRef] [PubMed]

44. Geisler, S.; Borresen-Dale, A.L.; Johnsen, H.; Aas, T.; Geisler, J.; Akslen, L.A.; Anker, G.; Lonning, P.E. TP53 gene mutations predict the response to neoadjuvant treatment with 5-fluorouracil and mitomycin in locally advanced breast cancer. Clin. Cancer Res. 2003, 9, 5582-5588. [PubMed]

45. Geisler, S.; Lonning, P.E.; Aas, T.; Johnsen, H.; Fluge, O.; Haugen, D.F.; Lillehaug, J.R.; Akslen, L.A.; Borresen-Dale, A.L. Influence of TP53 gene alterations and c-erbB-2 expression on the response to treatment with doxorubicin in locally advanced breast cancer. Cancer Res. 2001, 61, 2505-2512. [PubMed]

46. Do, P.M.; Varanasi, L.; Fan, S.; Li, C.; Kubacka, I.; Newman, V.; Chauhan, K.; Daniels, S.R.; Boccetta, M.; Garrett, M.R.; et al. Mutant p53 cooperates with ETS2 to promote etoposide resistance. Genes Dev. 2012, 26, 830-845. [CrossRef]

47. Fiorini, C.; Cordani, M.; Padroni, C.; Blandino, G.; Di Agostino, S.; Donadelli, M. Mutant p53 stimulates chemoresistance of pancreatic adenocarcinoma cells to gemcitabine. Biochim. Biophys. Acta 2015, 1853, 89-100. [CrossRef] [PubMed]

48. Iyer, S.V.; Parrales, A.; Begani, P.; Narkar, A.; Adhikari, A.S.; Martinez, L.A.; Iwakuma, T. Allele-specific silencing of mutant p53 attenuates dominant-negative and gain-of-function activities. Oncotarget 2016, 7, 5401-5415. [CrossRef]

49. Schulz-Heddergott, R.; Stark, N.; Edmunds, S.J.; Li, J.; Conradi, L.C.; Bohnenberger, H.; Ceteci, F.; Greten, F.R.; Dobbelstein, M.; Moll, U.M. Therapeutic Ablation of Gain-of-Function Mutant p53 in Colorectal Cancer Inhibits Stat3-Mediated Tumor Growth and Invasion. Cancer Cell 2018, 34, 298-314.e7. [CrossRef]

50. Alexandrova, E.M.; Yallowitz, A.R.; Li, D.; Xu, S.; Schulz, R.; Proia, D.A.; Lozano, G.; Dobbelstein, M.; Moll, U.M. Improving survival by exploiting tumour dependence on stabilized mutant p53 for treatment. Nature 2015, 523, 352-356. [CrossRef]

51. Ingallina, E.; Sorrentino, G.; Bertolio, R.; Lisek, K.; Zannini, A.; Azzolin, L.; Severino, L.U.; Scaini, D.; Mano, M.; Mantovani, F.; et al. Mechanical cues control mutant p53 stability through a mevalonate-RhoA axis. Nat. Cell Biol. 2018, 20, 28-35. [CrossRef] [PubMed]

52. Bykov, V.J.; Wiman, K.G. Mutant p53 reactivation by small molecules makes its way to the clinic. FEBS Lett. 2014, 588, 2622-2627. [CrossRef] [PubMed]

53. Bykov, V.J.N.; Eriksson, S.E.; Bianchi, J.; Wiman, K.G. Targeting mutant p53 for efficient cancer therapy. Nat. Rev. Cancer 2018, 18, 89-102. [CrossRef] [PubMed]

54. Blanden, A.R.; Yu, X.; Loh, S.N.; Levine, A.J.; Carpizo, D.R. Reactivating mutant p53 using small molecules as zinc metallochaperones: Awakening a sleeping giant in cancer. Drug Discov. Today 2015, 20, 1391-1397. [CrossRef] [PubMed]

55. Brown, C.J.; Cheok, C.F.; Verma, C.S.; Lane, D.P. Reactivation of p53: From peptides to small molecules. Trends Pharmacol. Sci. 2011, 32, 53-62. [CrossRef] [PubMed]

56. Weinmann, L.; Wischhusen, J.; Demma, M.J.; Naumann, U.; Roth, P.; Dasmahapatra, B.; Weller, M. A novel p53 rescue compound induces p53-dependent growth arrest and sensitises glioma cells to Apo2L/TRAIL-induced apoptosis. Cell Death Differ. 2008, 15, 718-729. [CrossRef] [PubMed]

57. Hiraki, M.; Hwang, S.Y.; Cao, S.; Ramadhar, T.R.; Byun, S.; Yoon, K.W.; Lee, J.H.; Chu, K.; Gurkar, A.U.; Kolev, V.; et al. Small-Molecule Reactivation of Mutant p53 to Wild-Type-like p53 through the p53-Hsp40 Regulatory Axis. Chem. Biol. 2015, 22, 1206-1216. [CrossRef] [PubMed]

58. Bykov, V.J.; Issaeva, N.; Shilov, A.; Hultcrantz, M.; Pugacheva, E.; Chumakov, P.; Bergman, J.; Wiman, K.G.; Selivanova, G. Restoration of the tumor suppressor function to mutant p53 by a low-molecular-weight compound. Nat. Med. 2002, 8, 282-288. [CrossRef]

59. Lane, D.; Levine, A. p53 Research: The past thirty years and the next thirty years. Cold Spring Harb. Perspect. Biol. 2010, 2, a000893. [CrossRef]

60. Bode, A.M.; Dong, Z. Post-translational modification of p53 in tumorigenesis. Nat. Rev. Cancer 2004, 4, 793-805. [CrossRef]

61. Dai, C.; Gu, W. p53 post-translational modification: Deregulated in tumorigenesis. Trends Mol. Med. 2010, 16, 528-536. [CrossRef] [PubMed]

62. Nguyen, T.A.; Menendez, D.; Resnick, M.A.; Anderson, C.W. Mutant TP53 posttranslational modifications: Challenges and opportunities. Hum. Mutat. 2014, 35, 738-755. [CrossRef] [PubMed] 
63. Wesierska-Gadek, J.; Bugajska-Schretter, A.; Cerni, C. ADP-ribosylation of p53 tumor suppressor protein: Mutant but not wild-type p53 is modified. J. Cell. Biochem. 1996, 62, 90-101. [CrossRef]

64. Bykov, V.J.; Lambert, J.M.; Hainaut, P.; Wiman, K.G. Mutant p53 rescue and modulation of p53 redox state. Cell Cycle 2009, 8, 2509-2517. [CrossRef] [PubMed]

65. Nomura, T.; Kamada, R.; Ito, I.; Chuman, Y.; Shimohigashi, Y.; Sakaguchi, K. Oxidation of methionine residue at hydrophobic core destabilizes p53 tetrameric structure. Biopolymers 2009, 91, 78-84. [CrossRef] [PubMed]

66. Kaar, J.L.; Basse, N.; Joerger, A.C.; Stephens, E.; Rutherford, T.J.; Fersht, A.R. Stabilization of mutant p53 via alkylation of cysteines and effects on DNA binding. Protein Sci. 2010, 19, 2267-2278. [CrossRef]

67. Yakovlev, V.A.; Bayden, A.S.; Graves, P.R.; Kellogg, G.E.; Mikkelsen, R.B. Nitration of the tumor suppressor protein p53 at tyrosine 327 promotes p53 oligomerization and activation. Biochemistry 2010, 49, 5331-5339. [CrossRef] [PubMed]

68. Donehower, L.A. Phosphatases reverse p53-mediated cell cycle checkpoints. Proc. Natl. Acad. Sci. USA 2014, 111, 7172-7173. [CrossRef]

69. Liu, C.; Zhu, Y.; Lou, W.; Nadiminty, N.; Chen, X.; Zhou, Q.; Shi, X.B.; deVere White, R.W.; Gao, A.C. Functional p53 determines docetaxel sensitivity in prostate cancer cells. Prostate 2013, 73, 418-427. [CrossRef]

70. Matsumoto, M.; Furihata, M.; Ohtsuki, Y. Posttranslational phosphorylation of mutant p53 protein in tumor development. Med. Mol. Morphol. 2006, 39, 79-87. [CrossRef]

71. Ullrich, S.J.; Sakaguchi, K.; Lees-Miller, S.P.; Fiscella, M.; Mercer, W.E.; Anderson, C.W.; Appella, E. Phosphorylation at Ser-15 and Ser-392 in mutant p53 molecules from human tumors is altered compared to wild-type p53. Proc. Natl. Acad. Sci. USA 1993, 90, 5954-5958. [CrossRef] [PubMed]

72. Minamoto, T.; Buschmann, T.; Habelhah, H.; Matusevich, E.; Tahara, H.; Boerresen-Dale, A.L.; Harris, C.; Sidransky, D.; Ronai, Z. Distinct pattern of p53 phosphorylation in human tumors. Oncogene 2001, 20, 3341-3347. [CrossRef] [PubMed]

73. Adorno, M.; Cordenonsi, M.; Montagner, M.; Dupont, S.; Wong, C.; Hann, B.; Solari, A.; Bobisse, S.; Rondina, M.B.; Guzzardo, V.; et al. A Mutant-p53/Smad complex opposes p63 to empower TGFbeta-induced metastasis. Cell 2009, 137, 87-98. [CrossRef] [PubMed]

74. Song, H.; Hollstein, M.; Xu, Y. p53 gain-of-function cancer mutants induce genetic instability by inactivating ATM. Nat. Cell Biol. 2007, 9, 573-580. [CrossRef] [PubMed]

75. Zerbini, L.F.; Wang, Y.; Correa, R.G.; Cho, J.Y.; Libermann, T.A. Blockage of NF-kappaB induces serine 15 phosphorylation of mutant p53 by JNK kinase in prostate cancer cells. Cell Cycle 2005, 4, 1247-1253. [CrossRef] [PubMed]

76. Sonego, M.; Schiappacassi, M.; Lovisa, S.; Dall'Acqua, A.; Bagnoli, M.; Lovat, F.; Libra, M.; D'Andrea, S.; Canzonieri, V.; Militello, L.; et al. Stathmin regulates mutant p53 stability and transcriptional activity in ovarian cancer. EMBO Mol. Med. 2013, 5, 707-722. [CrossRef] [PubMed]

77. Haupt, S.; di Agostino, S.; Mizrahi, I.; Alsheich-Bartok, O.; Voorhoeve, M.; Damalas, A.; Blandino, G.; Haupt, Y. Promyelocytic leukemia protein is required for gain of function by mutant p53. Cancer Res. 2009, 69, 4818-4826. [CrossRef] [PubMed]

78. Girardini, J.E.; Napoli, M.; Piazza, S.; Rustighi, A.; Marotta, C.; Radaelli, E.; Capaci, V.; Jordan, L.; Quinlan, P.; Thompson, A.; et al. A Pin1/mutant p53 axis promotes aggressiveness in breast cancer. Cancer Cell 2011, 20 , 79-91. [CrossRef]

79. Valenti, F.; Fausti, F.; Biagioni, F.; Shay, T.; Fontemaggi, G.; Domany, E.; Yaffe, M.B.; Strano, S.; Blandino, G.; Di Agostino, S. Mutant p53 oncogenic functions are sustained by Plk2 kinase through an autoregulatory feedback loop. Cell Cycle 2011, 10, 4330-4340. [CrossRef]

80. Matsumoto, M.; Furihata, M.; Kurabayashi, A.; Sasaguri, S.; Araki, K.; Hayashi, H.; Ohtsuki, Y. Prognostic significance of serine 392 phosphorylation in overexpressed p53 protein in human esophageal squamous cell carcinoma. Oncology 2004, 67, 143-150. [CrossRef]

81. Furihata, M.; Takeuchi, T.; Matsumoto, M.; Kurabayashi, A.; Ohtsuki, Y.; Terao, N.; Kuwahara, M.; Shuin, T. p53 mutation arising in Arg72 allele in the tumorigenesis and development of carcinoma of the urinary tract. Clin. Cancer Res. 2002, 8, 1192-1195. [PubMed]

82. Jethwa, A.; Slabicki, M.; Hullein, J.; Jentzsch, M.; Dalal, V.; Rabe, S.; Wagner, L.; Walther, T.; Klapper, W.; Project, M.N.; et al. TRRAP is essential for regulating the accumulation of mutant and wild-type p53 in lymphoma. Blood 2018, 131, 2789-2802. [CrossRef] 
83. Perez, R.E.; Knights, C.D.; Sahu, G.; Catania, J.; Kolukula, V.K.; Stoler, D.; Graessmann, A.; Ogryzko, V.; Pishvaian, M.; Albanese, C.; et al. Restoration of DNA-binding and growth-suppressive activity of mutant forms of p53 via a PCAF-mediated acetylation pathway. J. Cell. Physiol. 2010, 225, 394-405. [CrossRef] [PubMed]

84. Knowell, A.E.; Patel, D.; Morton, D.J.; Sharma, P.; Glymph, S.; Chaudhary, J. Id4 dependent acetylation restores mutant-p53 transcriptional activity. Mol. Cancer 2013, 12, 161. [CrossRef] [PubMed]

85. Yi, Y.W.; Kang, H.J.; Kim, H.J.; Kong, Y.; Brown, M.L.; Bae, I. Targeting mutant p53 by a SIRT1 activator YK-3-237 inhibits the proliferation of triple-negative breast cancer cells. Oncotarget 2013, 4, 984-994. [CrossRef] [PubMed]

86. Lukashchuk, N.; Vousden, K.H. Ubiquitination and degradation of mutant p53. Mol. Cell. Biol. 2007, 27, 8284-8295. [CrossRef] [PubMed]

87. Nie, L.; Sasaki, M.; Maki, C.G. Regulation of p53 nuclear export through sequential changes in conformation and ubiquitination. J. Biol. Chem. 2007, 282, 14616-14625. [CrossRef]

88. Frum, R.A.; Love, I.M.; Damle, P.K.; Mukhopadhyay, N.D.; Palit Deb, S.; Deb, S.; Grossman, S.R. Constitutive Activation of DNA Damage Checkpoint Signaling Contributes to Mutant p53 Accumulation via Modulation of p53 Ubiquitination. Mol. Cancer Res. MCR 2016, 14, 423-436. [CrossRef]

89. Zheng, T.; Wang, J.; Zhao, Y.; Zhang, C.; Lin, M.; Wang, X.; Yu, H.; Liu, L.; Feng, Z.; Hu, W. Spliced MDM2 isoforms promote mutant p53 accumulation and gain-of-function in tumorigenesis. Nat. Commun. 2013, 4, 2996. [CrossRef]

90. Yan, W.; Jung, Y.S.; Zhang, Y.; Chen, X. Arsenic trioxide reactivates proteasome-dependent degradation of mutant p53 protein in cancer cells in part via enhanced expression of Pirh2 E3 ligase. PLoS ONE 2014, 9, e103497. [CrossRef]

91. Yuan, J.; Luo, K.; Zhang, L.; Cheville, J.C.; Lou, Z. USP10 regulates p53 localization and stability by deubiquitinating p53. Cell 2010, 140, 384-396. [CrossRef] [PubMed]

92. Padmanabhan, A.; Candelaria, N.; Wong, K.K.; Nikolai, B.C.; Lonard, D.M.; O’Malley, B.W.; Richards, J.S. USP15-dependent lysosomal pathway controls p53-R175H turnover in ovarian cancer cells. Nat. Commun. 2018, 9, 1270. [CrossRef]

93. Peng, Y.; Chen, L.; Li, C.; Lu, W.; Chen, J. Inhibition of MDM2 by hsp90 contributes to mutant p53 stabilization. J. Biol. Chem. 2001, 276, 40583-40590. [CrossRef] [PubMed]

94. Li, D.; Marchenko, N.D.; Schulz, R.; Fischer, V.; Velasco-Hernandez, T.; Talos, F.; Moll, U.M. Functional inactivation of endogenous MDM2 and CHIP by HSP90 causes aberrant stabilization of mutant p53 in human cancer cells. Mol. Cancer Res. MCR 2011, 9, 577-588. [CrossRef] [PubMed]

95. Li, D.; Marchenko, N.D.; Moll, U.M. SAHA shows preferential cytotoxicity in mutant p53 cancer cells by destabilizing mutant p53 through inhibition of the HDAC6-Hsp90 chaperone axis. Cell Death Differ. 2011, 18, 1904-1913. [CrossRef] [PubMed]

96. Muller, P.; Hrstka, R.; Coomber, D.; Lane, D.P.; Vojtesek, B. Chaperone-dependent stabilization and degradation of p53 mutants. Oncogene 2008, 27, 3371-3383. [CrossRef] [PubMed]

97. Wiech, M.; Olszewski, M.B.; Tracz-Gaszewska, Z.; Wawrzynow, B.; Zylicz, M.; Zylicz, A. Molecular mechanism of mutant p53 stabilization: The role of HSP70 and MDM2. PLoS ONE 2012, 7, e51426. [CrossRef]

98. Lu, W.J.; Lee, N.P.; Kaul, S.C.; Lan, F.; Poon, R.T.; Wadhwa, R.; Luk, J.M. Mortalin-p53 interaction in cancer cells is stress dependent and constitutes a selective target for cancer therapy. Cell Death Differ. 2011, 18, 1046-1056. [CrossRef]

99. Ahn, B.Y.; Trinh, D.L.; Zajchowski, L.D.; Lee, B.; Elwi, A.N.; Kim, S.W. Tid1 is a new regulator of p53 mitochondrial translocation and apoptosis in cancer. Oncogene 2010, 29, 1155-1166. [CrossRef]

100. Tracz-Gaszewska, Z.; Klimczak, M.; Biecek, P.; Herok, M.; Kosinski, M.; Olszewski, M.B.; Czerwinska, P.; Wiech, M.; Wiznerowicz, M.; Zylicz, A.; et al. Molecular chaperones in the acquisition of cancer cell chemoresistance with mutated TP53 and MDM2 up-regulation. Oncotarget 2017, 8, 82123-82143. [CrossRef]

101. Yue, X.; Zhao, Y.; Liu, J.; Zhang, C.; Yu, H.; Wang, J.; Zheng, T.; Liu, L.; Li, J.; Feng, Z.; et al. BAG2 promotes tumorigenesis through enhancing mutant p53 protein levels and function. Elife 2015, 4. [CrossRef] [PubMed]

102. Yue, X.; Zhao, Y.; Huang, G.; Li, J.; Zhu, J.; Feng, Z.; Hu, W. A novel mutant p53 binding partner BAG5 stabilizes mutant p53 and promotes mutant p53 GOFs in tumorigenesis. Cell Discov. 2016, 2, 16039. [CrossRef] [PubMed] 
103. Marin, M.C.; Jost, C.A.; Brooks, L.A.; Irwin, M.S.; O’Nions, J.; Tidy, J.A.; James, N.; McGregor, J.M.; Harwood, C.A.; Yulug, I.G.; et al. A common polymorphism acts as an intragenic modifier of mutant p53 behaviour. Nat. Genet. 2000, 25, 47-54. [CrossRef] [PubMed]

104. Bergamaschi, D.; Gasco, M.; Hiller, L.; Sullivan, A.; Syed, N.; Trigiante, G.; Yulug, I.; Merlano, M.; Numico, G.; Comino, A.; et al. p53 polymorphism influences response in cancer chemotherapy via modulation of p73-dependent apoptosis. Cancer Cell 2003, 3, 387-402. [CrossRef]

105. Vikhanskaya, F.; Siddique, M.M.; Kei Lee, M.; Broggini, M.; Sabapathy, K. Evaluation of the combined effect of p53 codon 72 polymorphism and hotspot mutations in response to anticancer drugs. Clin. Cancer Res. 2005, 11, 4348-4356. [CrossRef] [PubMed]

106. Basu, S.; Gnanapradeepan, K.; Barnoud, T.; Kung, C.P.; Tavecchio, M.; Scott, J.; Watters, A.; Chen, Q.; Kossenkov, A.V.; Murphy, M.E. Mutant p53 controls tumor metabolism and metastasis by regulating PGC-1alpha. Genes Dev. 2018, 32, 230-243. [CrossRef] [PubMed]

107. Katz, C.; Low-Calle, A.M.; Choe, J.H.; Laptenko, O.; Tong, D.; Joseph-Chowdhury, J.N.; Garofalo, F.; Zhu, Y.; Friedler, A.; Prives, C. Wild-type and cancer-related p53 proteins are preferentially degraded by MDM2 as dimers rather than tetramers. Genes Dev. 2018, 32, 430-447. [CrossRef]

108. Jenkins, L.M.; Durell, S.R.; Mazur, S.J.; Appella, E. p53 N-terminal phosphorylation: A defining layer of complex regulation. Carcinogenesis 2012, 33, 1441-1449. [CrossRef]

109. Melnikova, V.O.; Santamaria, A.B.; Bolshakov, S.V.; Ananthaswamy, H.N. Mutant p53 is constitutively phosphorylated at Serine 15 in UV-induced mouse skin tumors: Involvement of ERK1/2 MAP kinase. Oncogene 2003, 22, 5958-5966. [CrossRef]

110. Ray, D.; Murphy, K.R.; Gal, S. The DNA binding and accumulation of p53 from breast cancer cell lines and the link with serine 15 phosphorylation. Cancer Biol. Ther. 2012, 13, 848-857. [CrossRef]

111. Sugikawa, E.; Yazaki, N.; Tsunoda, S.; Nakanishi, N.; Ohashi, M. Inhibition of mutant p53 phosphorylation at serine 15 or serine 315 partially restores the function of wild-type p53. Biochem. Biophys. Res. Commun. 1999, 261, 256-263. [CrossRef] [PubMed]

112. Ferbeyre, G.; de Stanchina, E.; Querido, E.; Baptiste, N.; Prives, C.; Lowe, S.W. PML is induced by oncogenic ras and promotes premature senescence. Genes Dev. 2000, 14, 2015-2027.

113. Alsheich-Bartok, O.; Haupt, S.; Alkalay-Snir, I.; Saito, S.; Appella, E.; Haupt, Y. PML enhances the regulation of p53 by CK1 in response to DNA damage. Oncogene 2008, 27, 3653-3661. [CrossRef]

114. Moller, A.; Sirma, H.; Hofmann, T.G.; Rueffer, S.; Klimczak, E.; Droge, W.; Will, H.; Schmitz, M.L. PML is required for homeodomain-interacting protein kinase 2 (HIPK2)-mediated p53 phosphorylation and cell cycle arrest but is dispensable for the formation of HIPK domains. Cancer Res. 2003, 63, 4310-4314.

115. Smeenk, L.; van Heeringen, S.J.; Koeppel, M.; Gilbert, B.; Janssen-Megens, E.; Stunnenberg, H.G.; Lohrum, M. Role of p53 serine 46 in p53 target gene regulation. PLoS ONE 2011, 6, e17574. [CrossRef] [PubMed]

116. Fukunaga-Takenaka, R.; Fukunaga, K.; Tatemichi, M.; Ohshima, H. Nitric oxide prevents UV-induced phosphorylation of the 53 tumor-suppressor protein at serine 46: A possible role in inhibition of apoptosis. Biochem. Biophys. Res. Commun. 2003, 308, 966-974. [CrossRef]

117. Mayo, L.D.; Seo, Y.R.; Jackson, M.W.; Smith, M.L.; Rivera Guzman, J.; Korgaonkar, C.K.; Donner, D.B. Phosphorylation of human p53 at serine 46 determines promoter selection and whether apoptosis is attenuated or amplified. J. Biol. Chem. 2005, 280, 25953-25959. [CrossRef]

118. Mantovani, F.; Tocco, F.; Girardini, J.; Smith, P.; Gasco, M.; Lu, X.; Crook, T.; Del Sal, G. The prolyl isomerase Pin1 orchestrates p53 acetylation and dissociation from the apoptosis inhibitor iASPP. Nat. Struct. Mol. Biol. 2007, 14, 912-920. [CrossRef]

119. Gillotin, S.; Yap, D.; Lu, X. Mutation at Ser392 specifically sensitizes mutant p53H175 to mdm2-mediated degradation. Cell Cycle 2010, 9, 1390-1398. [CrossRef]

120. Yap, D.B.; Hsieh, J.K.; Zhong, S.; Heath, V.; Gusterson, B.; Crook, T.; Lu, X. Ser392 phosphorylation regulates the oncogenic function of mutant p53. Cancer Res. 2004, 64, 4749-4754. [CrossRef]

121. Kruse, J.P.; Gu, W. Modes of p53 regulation. Cell 2009, 137, 609-622. [CrossRef] [PubMed]

122. Luo, J.; Su, F.; Chen, D.; Shiloh, A.; Gu, W. Deacetylation of p53 modulates its effect on cell growth and apoptosis. Nature 2000, 408, 377-381. [CrossRef] [PubMed]

123. Vaziri, H.; Dessain, S.K.; Ng Eaton, E.; Imai, S.I.; Frye, R.A.; Pandita, T.K.; Guarente, L.; Weinberg, R.A. hSIR2(SIRT1) functions as an NAD-dependent p53 deacetylase. Cell 2001, 107, 149-159. [CrossRef] 
124. Reed, S.M.; Quelle, D.E. p53 Acetylation: Regulation and Consequences. Cancers 2014, 7, 30-69. [CrossRef] [PubMed]

125. Brooks, C.L.; Gu, W. The impact of acetylation and deacetylation on the p53 pathway. Protein Cell 2011, 2, 456-462. [CrossRef] [PubMed]

126. Warnock, L.J.; Raines, S.A.; Milner, J. Aurora A mediates cross-talk between N- and C-terminal post-translational modifications of p53. Cancer Biol. Ther. 2011, 12, 1059-1068. [CrossRef] [PubMed]

127. Murr, R.; Vaissiere, T.; Sawan, C.; Shukla, V.; Herceg, Z. Orchestration of chromatin-based processes: Mind the TRRAP. Oncogene 2007, 26, 5358-5372. [CrossRef] [PubMed]

128. Joerger, A.C.; Fersht, A.R. Structure-function-rescue: The diverse nature of common p53 cancer mutants. Oncogene 2007, 26, 2226-2242. [CrossRef]

129. Zhang, Z.Y.; Hong, D.; Nam, S.H.; Kim, J.M.; Paik, Y.H.; Joh, J.W.; Kwon, C.H.; Park, J.B.; Choi, G.S.; Jang, K.Y.; et al. SIRT1 regulates oncogenesis via a mutant p53-dependent pathway in hepatocellular carcinoma. J. Hepatol. 2015, 62, 121-130. [CrossRef]

130. Li, M.; Brooks, C.L.; Wu-Baer, F.; Chen, D.; Baer, R.; Gu, W. Mono- versus polyubiquitination: Differential control of p53 fate by Mdm2. Science 2003, 302, 1972-1975. [CrossRef]

131. Carter, S.; Bischof, O.; Dejean, A.; Vousden, K.H. C-terminal modifications regulate MDM2 dissociation and nuclear export of p53. Nat. Cell Biol. 2007, 9, 428-435. [CrossRef] [PubMed]

132. Shan, J.; Brooks, C.; Kon, N.; Li, M.; Gu, W. Dissecting roles of ubiquitination in the p53 pathway. In Ernst Schering Foundation Symposium Proceedings; Springer: Berlin/Heidelberg, Germany, 2008; pp. 127-136.

133. Brooks, C.L.; Gu, W. p53 regulation by ubiquitin. FEBS Lett. 2011, 585, 2803-2809. [CrossRef] [PubMed]

134. Bartel, F.; Taubert, H.; Harris, L.C. Alternative and aberrant splicing of MDM2 mRNA in human cancer. Cancer Cell 2002, 2, 9-15. [CrossRef]

135. Schuster, K.; Fan, L.; Harris, L.C. MDM2 splice variants predominantly localize to the nucleoplasm mediated by a COOH-terminal nuclear localization signal. Mol. Cancer Res. MCR 2007, 5, 403-412. [CrossRef] [PubMed]

136. Evans, S.C.; Viswanathan, M.; Grier, J.D.; Narayana, M.; El-Naggar, A.K.; Lozano, G. An alternatively spliced HDM2 product increases p53 activity by inhibiting HDM2. Oncogene 2001, 20, 4041-4049. [CrossRef] [PubMed]

137. Chandler, D.S.; Singh, R.K.; Caldwell, L.C.; Bitler, J.L.; Lozano, G. Genotoxic stress induces coordinately regulated alternative splicing of the p53 modulators MDM2 and MDM4. Cancer Res. 2006, 66, 9502-9508. [CrossRef] [PubMed]

138. Jiang, J.; Ballinger, C.A.; Wu, Y.; Dai, Q.; Cyr, D.M.; Hohfeld, J.; Patterson, C. CHIP is a U-box-dependent E3 ubiquitin ligase: Identification of Hsc70 as a target for ubiquitylation. J. Biol. Chem. 2001, 276, 42938-42944. [CrossRef]

139. Esser, C.; Scheffner, M.; Hohfeld, J. The chaperone-associated ubiquitin ligase CHIP is able to target p53 for proteasomal degradation. J. Biol. Chem. 2005, 280, 27443-27448. [CrossRef]

140. Zou, Q.; Jin, J.; Hu, H.; Li, H.S.; Romano, S.; Xiao, Y.; Nakaya, M.; Zhou, X.; Cheng, X.; Yang, P.; et al. USP15 stabilizes MDM2 to mediate cancer-cell survival and inhibit antitumor T cell responses. Nat. Immunol. 2014, 15, 562-570. [CrossRef]

141. Jolly, C.; Morimoto, R.I. Role of the heat shock response and molecular chaperones in oncogenesis and cell death. J. Natl. Cancer Inst. 2000, 92, 1564-1572. [CrossRef]

142. Muller, L.; Schaupp, A.; Walerych, D.; Wegele, H.; Buchner, J. Hsp90 regulates the activity of wild type p53 under physiological and elevated temperatures. J. Biol. Chem. 2004, 279, 48846-48854. [CrossRef] [PubMed]

143. Selkirk, J.K.; Merrick, B.A.; Stackhouse, B.L.; He, C. Multiple p53 protein isoforms and formation of oligomeric complexes with heat shock proteins Hsp70 and Hsp90 in the human mammary tumor, T47D, cell line. Appl. Theor. Electrophor. 1994, 4, 11-18. [PubMed]

144. Hainaut, P.; Milner, J. Interaction of heat-shock protein 70 with p53 translated in vitro: Evidence for interaction with dimeric p53 and for a role in the regulation of p53 conformation. EMBO J. 1992, 11, 3513-3520. [CrossRef] [PubMed]

145. Sturzbecher, H.W.; Chumakov, P.; Welch, W.J.; Jenkins, J.R. Mutant p53 proteins bind hsp $72 / 73$ cellular heat shock-related proteins in SV40-transformed monkey cells. Oncogene 1987, 1, 201-211. [PubMed] 
146. Sugito, K.; Yamane, M.; Hattori, H.; Hayashi, Y.; Tohnai, I.; Ueda, M.; Tsuchida, N.; Ohtsuka, K. Interaction between hsp70 and hsp40, eukaryotic homologues of DnaK and DnaJ, in human cells expressing mutant-type p53. FEBS Lett. 1995, 358, 161-164. [CrossRef]

147. Blagosklonny, M.V.; Toretsky, J.; Bohen, S.; Neckers, L. Mutant conformation of p53 translated in vitro or in vivo requires functional HSP90. Proc. Natl. Acad. Sci. USA 1996, 93, 8379-8383. [CrossRef] [PubMed]

148. Iwaya, K.; Tsuda, H.; Fujita, S.; Suzuki, M.; Hirohashi, S. Natural state of mutant p53 protein and heat shock protein 70 in breast cancer tissues. Lab. Investig. 1995, 72, 707-714. [PubMed]

149. Whitesell, L.; Sutphin, P.D.; Pulcini, E.J.; Martinez, J.D.; Cook, P.H. The physical association of multiple molecular chaperone proteins with mutant 553 is altered by geldanamycin, an hsp90-binding agent. Mol. Cell. Biol. 1998, 18, 1517-1524. [CrossRef]

150. Nagata, Y.; Anan, T.; Yoshida, T.; Mizukami, T.; Taya, Y.; Fujiwara, T.; Kato, H.; Saya, H.; Nakao, M. The stabilization mechanism of mutant-type p53 by impaired ubiquitination: The loss of wild-type p53 function and the hsp90 association. Oncogene 1999, 18, 6037-6049. [CrossRef]

151. Lin, K.; Rockliffe, N.; Johnson, G.G.; Sherrington, P.D.; Pettitt, A.R. Hsp90 inhibition has opposing effects on wild-type and mutant p53 and induces p21 expression and cytotoxicity irrespective of p53/ATM status in chronic lymphocytic leukaemia cells. Oncogene 2008, 27, 2445-2455. [CrossRef]

152. Kovacs, J.J.; Murphy, P.J.; Gaillard, S.; Zhao, X.; Wu, J.T.; Nicchitta, C.V.; Yoshida, M.; Toft, D.O.; Pratt, W.B.; Yao, T.P. HDAC6 regulates Hsp90 acetylation and chaperone-dependent activation of glucocorticoid receptor. Mol. Cell 2005, 18, 601-607. [CrossRef] [PubMed]

153. Finlay, C.A.; Hinds, P.W.; Tan, T.H.; Eliyahu, D.; Oren, M.; Levine, A.J. Activating mutations for transformation by p53 produce a gene product that forms an hsc70-p53 complex with an altered half-life. Mol. Cell. Biol. 1988, 8, 531-539. [CrossRef] [PubMed]

154. Black, J.D.; Rezvani, K. Heat Shock Protein 70s as Potential Molecular Targets for Colon Cancer Therapeutics. Curr. Med. Chem. 2016, 23, 3171-3188. [CrossRef] [PubMed]

155. Walker, C.; Bottger, S.; Low, B. Mortalin-based cytoplasmic sequestration of p53 in a nonmammalian cancer model. Am. J. Pathol. 2006, 168, 1526-1530. [CrossRef]

156. King, F.W.; Wawrzynow, A.; Hohfeld, J.; Zylicz, M. Co-chaperones Bag-1, Hop and Hsp40 regulate Hsc70 and Hsp90 interactions with wild-type or mutant p53. EMBO J. 2001, 20, 6297-6305. [CrossRef] [PubMed]

157. Trinh, D.L.; Elwi, A.N.; Kim, S.W. Direct interaction between p53 and Tid1 proteins affects p53 mitochondrial localization and apoptosis. Oncotarget 2010, 1, 396-404. [CrossRef] [PubMed]

158. Dumont, P.; Leu, J.I.; Della Pietra, A.C., 3rd; George, D.L.; Murphy, M. The codon 72 polymorphic variants of p53 have markedly different apoptotic potential. Nat. Genet. 2003, 33, 357-365. [CrossRef]

159. Gaiddon, C.; Lokshin, M.; Ahn, J.; Zhang, T.; Prives, C. A subset of tumor-derived mutant forms of p53 down-regulate 63 and p73 through a direct interaction with the p53 core domain. Mol. Cell. Biol. 2001, 21, 1874-1887. [CrossRef]

160. Di Como, C.J.; Gaiddon, C.; Prives, C. p73 function is inhibited by tumor-derived p53 mutants in mammalian cells. Mol. Cell. Biol. 1999, 19, 1438-1449. [CrossRef]

161. Strano, S.; Munarriz, E.; Rossi, M.; Cristofanelli, B.; Shaul, Y.; Castagnoli, L.; Levine, A.J.; Sacchi, A.; Cesareni, G.; Oren, M.; et al. Physical and functional interaction between p53 mutants and different isoforms of p73. J. Biol. Chem. 2000, 275, 29503-29512. [CrossRef]

162. Strano, S.; Rossi, M.; Fontemaggi, G.; Munarriz, E.; Soddu, S.; Sacchi, A.; Blandino, G. From p63 to p53 across p73. FEBS Lett. 2001, 490, 163-170. [CrossRef]

163. Luo, J.L.; Yang, Q.; Tong, W.M.; Hergenhahn, M.; Wang, Z.Q.; Hollstein, M. Knock-in mice with a chimeric human/murine p53 gene develop normally and show wild-type p53 responses to DNA damaging agents: A new biomedical research tool. Oncogene 2001, 20, 320-328. [CrossRef] [PubMed]

164. Leu, J.I.; Murphy, M.E.; George, D.L. The p53 Codon 72 Polymorphism Modifies the Cellular Response to Inflammatory Challenge in the Liver. J. Liver 2013, 2, 117. [PubMed]

165. Kamada, R.; Toguchi, Y.; Nomura, T.; Imagawa, T.; Sakaguchi, K. Tetramer formation of tumor suppressor protein p53: Structure, function, and applications. Biopolymers 2016, 106, 598-612. [CrossRef] [PubMed]

(C) 2018 by the authors. Licensee MDPI, Basel, Switzerland. This article is an open access article distributed under the terms and conditions of the Creative Commons Attribution (CC BY) license (http:/ / creativecommons.org/licenses/by/4.0/). 